\title{
American Indian Adolescents Access to and Involvement in In- School Extracurricular Activities in Relation To Substance Use Frequency and Risk Behaviors
}

\author{
Elizabeth A. Jones \\ West Virginia University
}

Follow this and additional works at: https://researchrepository.wvu.edu/etd

\footnotetext{
Recommended Citation

Jones, Elizabeth A., "American Indian Adolescents Access to and Involvement in In-School Extracurricular Activities in Relation To Substance Use Frequency and Risk Behaviors" (2013). Graduate Theses, Dissertations, and Problem Reports. 457.

https://researchrepository.wvu.edu/etd/457

This Thesis is protected by copyright and/or related rights. It has been brought to you by the The Research Repository @ WVU with permission from the rights-holder(s). You are free to use this Thesis in any way that is permitted by the copyright and related rights legislation that applies to your use. For other uses you must obtain permission from the rights-holder(s) directly, unless additional rights are indicated by a Creative Commons license in the record and/ or on the work itself. This Thesis has been accepted for inclusion in WVU Graduate Theses, Dissertations, and Problem Reports collection by an authorized administrator of The Research Repository @ WVU. For more information, please contact researchrepository@mail.wvu.edu.
} 
American Indian Adolescents Access to and Involvement in In-School Extracurricular Activities in Relation To Substance Use Frequency and Risk Behaviors

\author{
Elizabeth A. Jones
}

Thesis submitted to the College of Education and Human Services At West Virginia University

In partial fulfillment of the requirements for the degree of

Master of Arts

In Educational Psychology

With an emphasis in Child Development and Family Studies

Carol A. Markstrom, Ph.D., Committee Chairperson Kristin L. Moilanen, Ph.D., Member Aaron Metzger, Ph.D., Member

Department of Learning Sciences and Human Development

Morgantown, West Virginia

2013

Keywords: American Indian; Adolescents; Activities; Substance Use Copyright 2013 Elizabeth A. Jones 


\begin{abstract}
American Indian Adolescents Access to and Involvement in In-School Extracurricular Activities in Relation To Substance Use Frequency and Risk Behaviors

Elizabeth Jones
\end{abstract}

This thesis looks at the protective benefits that involvement in adult-led in-school extracurricular activities had on the use of drugs and alcohol by $8^{\text {th }}, 10^{\text {th }}$, and $12^{\text {th }}$ grade American Indian adolescents in Arizona. This population has been chosen because they have a history of oppression, substance abuse, and prejudice. These adolescents represent an extremely at-risk population due to historical trauma and the present-day responses to this trauma. The researcher used data previously collected by the Arizona Youth Survey in 2010 and looked at it through the lens of Hirschi's Social Control Theory and the protective model of resilience. Hirschi's theory states that deviance is caused by a lack of a bond to society and can possibly be prevented by (a) attachment, (b) commitment, (c) involvement, and (d) belief (Hirschi, 2002). Participation in adult-led in-school extracurricular activities can enhance the type of bonding Hirshi identified. The protective model of resilience explains how a particular resource might reduce the negative effects of a risk factor present in an individual's life thereby minimizing the chance for problem behavior outcomes such as substance abuse (Bernat \& Resnick, 2009). The researcher found that an adolescent's participation in adult-led in-school extracurricular activities was: (a) related to a lower instance of risky substance abuse activities such as being drunk or high at school and (b) related to a lower engagement in the individual's use of drugs and alcohol. 


\section{ACKNOWLEDGMENTS}

I would like to thank my family, immediate and extended, for their support and interest in my research over the past two years. A special thanks to my fiancé, John Ramirez, who moved across the country, from Arizona, so he could lend support while I finished my degree in West Virginia. I would also like to thank Ms. Amanda Webster who has been so helpful in suggesting pieces of literature and also in the formatting of this document. Additionally, a special thank you is extended to my academic advisor and committee chair, Dr. Carol Markstrom who guided the entire research process from beginning to end. This would not be possible without the support and guidance of the rest of my thesis committee, Dr. Aaron Metzger and Dr. Kristin Moilanen. 


\section{TABLE OF CONTENTS}

Page

Title Page................................................................ 1

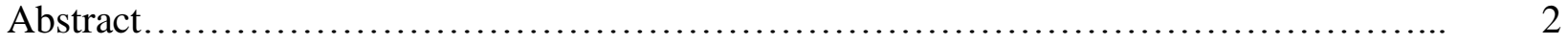

Acknowledgements..................................................... 3

Table of Contents....................................................... 4

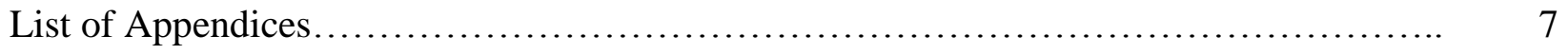

List of Tables........................................................... 8

List of Figures........................................................ 9

Chapter One: Introduction............................................... 11

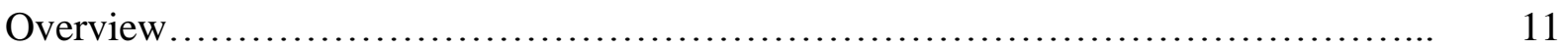

Statement of the Problem.................................................. 14

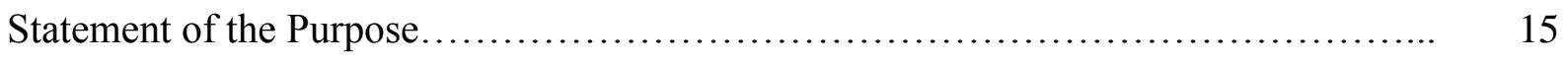

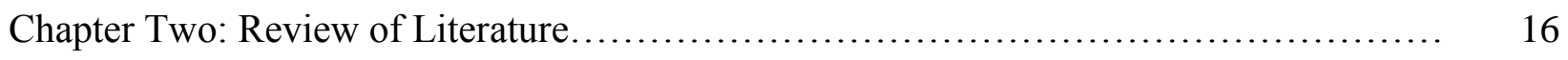

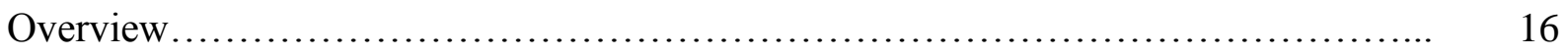

American Indian Demographics.......................................... 17

Theoretical Perspectives................................................ 18

Social Control Theory............................................... 18

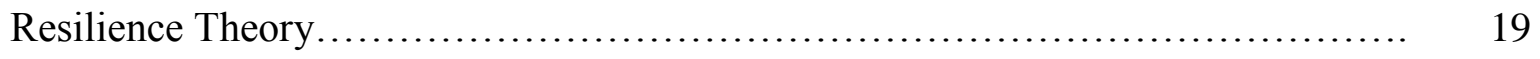

Risk and Protective Factors........................................... 21

Risk Factors....................................................... 21

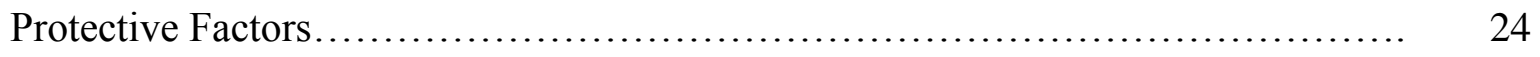

Adult-Led In-School Extracurricular Activities and Substance Use and Abuse......... 27 
Chapter Three: Methods..................................................... 41

Research Design........................................................... 41

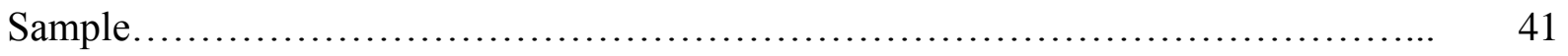

Procedures................................................................. 43

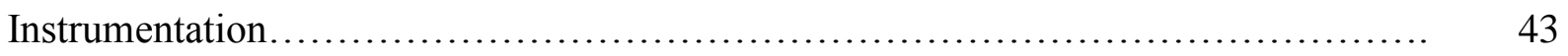

Frequency of Substance Use......................................... 44

Risky Substance Use Behaviors.................................... 45

Extracurricular Availability and Frequency of Participation.................... 45

Chapter Four: Results................................................. 47

Preliminary Analyses.................................................... 47

Primary Analyses: Availability.......................................... 49

Alcohol............................................................ 49

Marijuana............................................................. 49

Illicit Drugs........................................................ 50

Prescription Drugs................................................. 50

Over the Counter Drugs.............................................. 50

Drunk/High at School............................................. 50

Ride/drive Drunk.................................................. 50

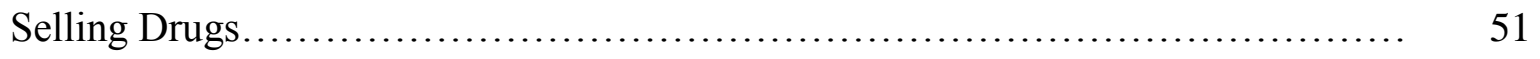

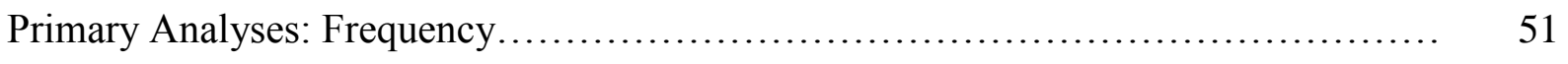

Alcohol.......................................................... 51

Marijuana.......................................................... 51

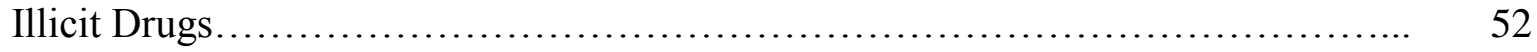


Prescription Drugs.................................................. 52

Over the Counter Drugs.................................................. 52

Drunk/High at School............................................... 52

Ride/Drive Drunk..................................................... 53

Selling Drugs....................................................... 54

Primary Analyses: Number............................................ 54

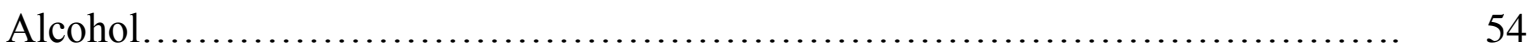

Marijuana........................................................... 54

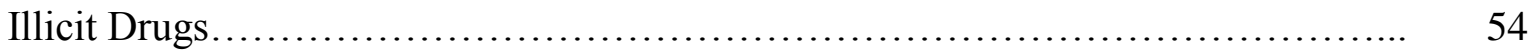

Prescription Drugs................................................... 55

Over the Counter Drugs................................................. 55

Drunk $/$ High at School................................................. 55

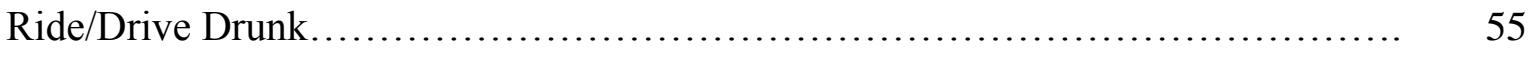

Selling Drugs...................................................... 55

Chapter Five: Discussion.............................................. 56

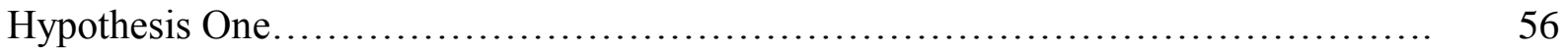

Hypothesis Two.................................................. 59

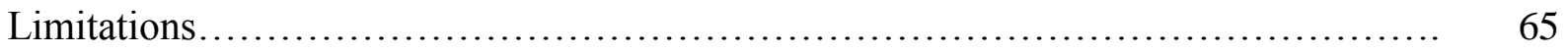

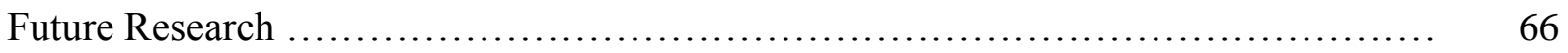

Conclusions and Applied Implications................................... 67

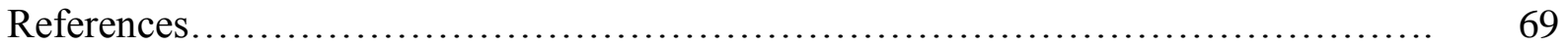

Appendices........................................................... 74 


\section{List of Appendices}

Appendix A: Arizona Youth Survey .............................................. 74

Appendix B: Example Parent Informational Letter.................................. 78

Appendix C: Data Sharing Agreement.............................................. 79 


\section{List of Tables}

Table 1: Demographics for Sample........................................... 83

Table 2: Table of Variables.................................................... 84

Table 3: Summary of Bivariate Correlations Between Dependent and Independent

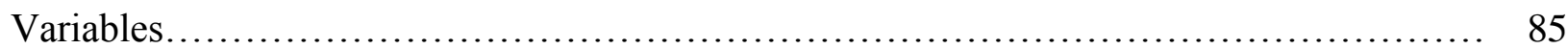

Table 4: T-test Information Regarding Gender................................ 86

Table 5: T-test Information Regarding Metropolitan versus Non-Metropolitan Status....... 87

Table 6: T-test Information Regarding Reservation versus Non-Reservation Status......... 88

Table 7: Summary of Regression Models Predicting Substance Use From Availability of In-School Extracurricular Activities.......................................... 89

Table 8: Summary of Regression Models Predicting Substance Use From Frequency of Involvement in In-School Extracurricular Activities............................... 90

Table 9:Summary of Regression Models Predicting Substance Use From Number Of In-

School Extracurricular Activities Adolescents are Involved In...................... 91 


\section{List of Figures}

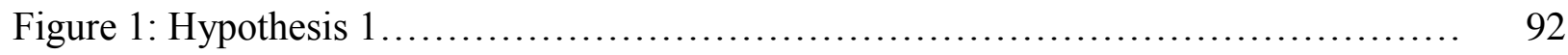

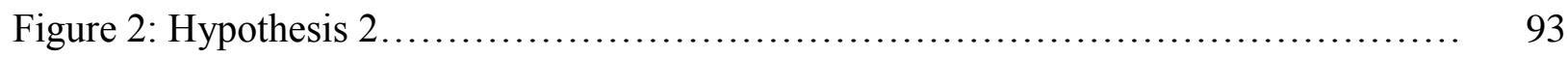

Figure 3: Interaction of Availability of Adult-Led In-School Extracurricular Activities,

Metropolitan Status, and Reported Alcohol Use in the Past 30 Days................... 94

Figure 4: Interaction of Availability of Adult-Led In-School Extracurricular Activities,

Gender, and Reported Marijuana Use in the Past 30 Days........................... 95

Figure 5: Interaction of Availability of Adult-Led In-School Extracurricular Activities,

Metropolitan Status, and Reported Marijuana Use in the Past 30 Days.................. 96

Figure 6: Interaction of Availability of Adult-Led In-School Extracurricular Activities,

Gender, and Reported Prescription Drug Use in the Past 30 Days..................... 97

Figure 7: Interaction of Availability of Adult-Led In-School Extracurricular Activities,

Metropolitan Status, and Reported Being Drunk or High at School in the Past 30 Days......

Figure 8: Interaction of Availability of Adult-Led In-School Extracurricular Activities,

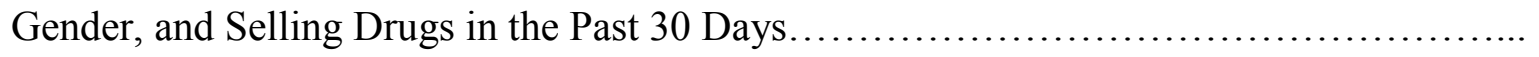

Figure 9: Interaction of Availability of Adult-Led In-School Extracurricular Activities,

Metropolitan Status, and Selling Drugs in the Past 30 Days........................... 100

Figure 10: Interaction of Frequency of Involvement in Adult-Led In-School

Extracurricular Activities, Reservation Status, and Reported Alcohol Use in the Past 30

Days.....................................................................

Figure 11: Interaction of Frequency of Involvement in Adult-Led In-School

Extracurricular Activities, Reservation Status, and Reported Marijuana Use in the Past 30 
Days

Figure 12: Interaction of Frequency of Involvement in Adult-Led In-School

Extracurricular Activities, Metropolitan Status, and Reported Marijuana Use in the Past 30

Days.

Figure 13: Interaction of Frequency of Involvement in Adult-Led In-School

Extracurricular Activities, Reservation Status, and Reported Being Drunk or High at

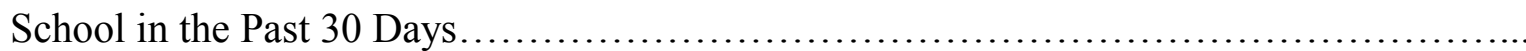

104

Figure 14: Interaction of Frequency of Involvement in Adult-Led In-School

Extracurricular Activities, Metropolitan Status, and Reported Being Drunk or High at

School in the Past 30 Days

Figure 15: Interaction of Frequency of Involvement in Adult-Led In-School

Extracurricular Activities, Gender, and Reported Riding with an Intoxicated Individual or

Driving a Vehicle While Intoxicated in the Past 30 Days

Figure 16: Interaction of Frequency of Involvement in Adult-Led In-School

Extracurricular Activities, Reservation Status, and Reported Riding with an Intoxicated

Individual or Driving a Vehicle While Intoxicated in the Past 30 Days...................

Figure 17: Interaction of Frequency of Involvement in Adult-Led In-School

Extracurricular Activities, Metropolitan Status, and Reported Riding with an Intoxicated

Individual or Driving a Vehicle While Intoxicated in the Past 30 Days

108

Figure 18: Interaction of Frequency of Involvement in Adult-Led In-School

Extracurricular Activities, Metropolitan Status, and Selling Drugs in the Past 30 Days.....

Figure 19: Interaction of Number of Adult-Led In-School Extracurricular Activities

Adolescents are Involved In, Metropolitan Status, and Selling Drugs in the Past 30 Days... 


\section{Chapter 1}

\section{Introduction}

\section{Overview}

All behaviors, normative and deviant, are influenced through a variety of sources: parents, siblings, peers, caregivers, teachers, coaches, and even the media (Taylor \& Turek, 2010). For generations parents have been enrolling their adolescents in adult-led in-school extracurricular activities in hopes that they will learn skills they may carry with them throughout their lives. Parents do this as they want their adolescents to have new experiences, develop interests, make new friends, and also to promote positive development. As individuals make the transition into elementary school parents become a less salient socializing agent in their lives and teachers and peers start to have more influence as more time is spent in those environments away from home (Taylor \& Turek, 2010). These individuals then make another transition from elementary school to middle or high school resulting in peers taking on a more powerful socializing role (Taylor \& Turek, 2010).

Adult-led in-school extracurricular activities provide opportunities for adolescent peers to engage socially in a supervised environment. Taylor and Turek (2010) suggest that organized sports (as an example of one type of extracurricular activity) have historically been used as a means of social control and are used to replace any delinquent types of activities in which children and adolescents might previously have been involved in or could potentially become involved. For example, delinquent activities would include skipping or dropping out of school, destroying property, stealing, and engaging in substance use or abuse (Taylor \& Turek, 2010). Travis Hirschi (2002) developed a theory referred to as social control theory of delinquency. In this theory, Hirschi suggested that delinquency is the result of a lack of bond to society through 
means of attachment, commitment, involvement, or belief. Adult-led extracurricular activities could allow opportunities for involvement with same age peers in prosocial activities under the direct supervision of adult volunteers which might decrease the occurrence of delinquent activities (Hirschi, 2002; Peretti-Watel, Beck, \& Legleye, 2002; Taylor \& Turek, 2010). Adolescence is a time of personal exploration, and unfortunately for many individuals, a time for experimentation with a variety of substances including cigarettes, marijuana, alcohol, pharmaceuticals, and other illicit drugs. Adult-led extracurricular activities have been suggested to be effective in protecting individuals from substance use and abuse (Shilts, 1991; Elder, et al., 2000; Eccles \& Barber, 1999). For example Peretti-Watel et al. (2002), found that adolescents who were involved in supervised club sports reported significantly lower rates of substance use than adolescents who reported playing sports unsupervised with friends. Hirschi (2002) suggested that this protection occurs simply as the activity has filled the block of free time the individual might have spent participating in delinquent activities. Availability to adult-led inschool extracurricular activities is an important consideration as funding for adult-led in-school extracurricular activities is consistently being cut in many schools. Therefore, the opportunity for involvement in these types of activities may be limited for some adolescents. If adult-led inschool extracurricular activities are not available then the adolescent does not even have a choice to be a part of these activities. Existing literature rarely focuses on availability of activities and only concentrates on the adolescent's actual involvement in activities.

There is limited research on American Indian adolescents and prevention or intervention strategies for substance use. There is very little research examining the availability of adult-led in-school extracurricular activities to this population and the impact their subsequent involvement has on their substance use and abuse. American Indian adolescents are a part of a 
historically traumatized and at-risk population for developing problem behaviors, and research indicates the substance abuse risk among this population. Beauvais, Jumper-Thurman, and Burnside (2007) conducted a longitudinal study which tracked the substance use of separate cohorts of American Indian adolescent substance use that lived on reservations compared to nonAmerican Indian students. Over the past 30 years American Indian adolescents reported consistently higher rates of lifetime substance use over non-American Indian adolescents. Along with higher rates of lifetime substance use, American Indian adolescents report their first use of substances to be at much younger ages than non-American Indian adolescents (Beauvais et al., 2007; Osilla, Lonczak, Mail, Larimer, \& Marlatt, 2007). These researchers suggested that American Indian adolescents are participating in substance use and abuse activities more frequently than non-American Indian adolescents due to the fact that substance use and abuse is prevalent in their environments (Beauvais et al., 2007).

According to Sutton (2008), today two thirds of the American Indian population are living off of reservation land. Little research accounts for the difference between American Indian adolescent environments such as living on reservation land and those not living on reservation land. Also, the distinction of American Indian adolescents living in a metropolitan versus non-metropolitan area is rarely mentioned in existing literature. These distinctions are important to assess as reservation land can be located in both metropolitan and non-metropolitan areas. Substance use and abuse may differ depending on this population's distinct environmental categories. While many American Indian individuals no longer live on reservation land, perhaps the higher substance use and abuse results of Beauvais et al. (2007) could partially be attributed to those living on reservation lands as they may not have access to protective resources such as adult-led in-school extracurricular activities. This study will address some of these gaps in the 
existing literature on American Indian adolescent substance use and abuse.

\section{Statement of the Problem}

According to the Center for Disease Control and Prevention (CDC, 2001), the three leading causes of death of 15-24 year old American Indian/Alaskan Natives are substance related, specifically, injuries attributable to car accidents, suicide, and homicide. In a study conducted by the CDC (2001) with high school students enrolled in schools funded by the Bureau of Indian Affairs, 81\% of these students reported any lifetime alcohol use, with 49\% currently using alcohol. In this same study, 50\% of high school students reported current marijuana use and 57\% reported current cigarette use (CDC, 2001). For some members of this population, substance abuse is a normative way of life and can be viewed as an informal transition into adulthood. Very little research has been conducted on the protective mechanisms at work in the American Indian population, with research focused primarily on the problems these communities face. Previous research studies with any population looking at the relationship between substance use and adult-led in-school extracurricular activities rarely report if these activities are even available to adolescents in the study. Therefore, this thesis will aid in filling this gap in the current literature on the availability of and involvement in adult-led in-school extracurricular activities as a method for substance use prevention among the American Indian adolescent population. Adult-led in-school extracurricular activities have been shown to function as a protective factor against delinquent behaviors, such as substance abuse, in previous research with other non-Native adolescent populations (Cooley et al., 2001; Eccles \& Barber, 1999; Elder, Leaver-Dunn, Wang, Nagy, \& Green, 2000; Shilts, 1991). Perhaps the most significant issue found in current literature is that reservation versus non-reservation, and metropolitan versus non-metropolitan are not examined as moderating variables in regard to adolescent substance use 
and abuse.

\section{Statement of Purpose}

This study was conducted due to the high incidence levels of substance abuse among American Indian youth and the lack of research on the role of adult-led in-school extracurricular activities as protective factors. One purpose of this study was to evaluate if availability of adultled in-school extracurricular activities was related to lower substance usage and less engagement in risky substance abuse activities. In this study, risky substance abuse behavior was categorized as being drunk or high at school, riding in a vehicle with an intoxicated driver, driving a vehicle while intoxicated, or selling drugs. A second purpose of this study was to examine adolescent involvement in adult-led in-school extracurricular activities to see if greater involvement was related to lower substance usage and less engagement in risky substance use activities. Gender, metropolitan versus non-metropolitan status, and reservation versus non-reservation status were examined in these hypotheses as moderating variables. Looking at moderating effects was important, as little existing research is concerned with moderating effects which could potentially play a role in determining in what ways adult-led in-school extracurricular activities and substance use and abuse are related for this population. 


\section{Chapter 2}

\section{Review of Literature}

\section{Overview}

Demographic information regarding the American Indian adolescent population is reviewed as a portion of the literature review, including information describing historical and other factors experienced by American Indian adolescents that heighten risk for developing problem behaviors. Then, a short review of social control theory and the protective model of resilience theory is presented to explain how they complement each other and offer an applicable conceptualization for this study. Social control theory posits that an individual may be deterred from participating in delinquent activities if they form (a) an attachment, (b) a commitment, (c) involvement, and/or (d) a belief in a particular activity, organization, or institution (Bernat \& Resnick, 2009). The delinquent act of focus for this thesis is adolescent substance use and abuse and the activity of focus is adult-led in-school extracurricular activities. As the protective model of resilience theory states, an individual may not experience resilience unless they are exposed to risk, and then have a protective factor present to protect them from becoming involved in delinquent behaviors (Bernat \& Resnick, 2009). Risk and protective factors unique to American Indian adolescents are then addressed in the next section. The review of literature concludes with a review of research studies conducted with adolescents concerning availability and involvement in adult-led in-school extracurricular activities, and the relation to usage of substances. Upon review of recent research, hypotheses related to the purposes of this study are generated and then tested using data from the 2010 Arizona Youth Survey (2010a). 


\section{American Indian Demographics}

The 2010 Census identifies American Indian or Alaskan Native(AI/AN) individuals as those who have origin with any peoples originally found in North and South American who still hold some tribal affiliation or attachment (U.S. Census Bureau, 2012d). According to Sutton (2008), prior to European contact with North American Indigenous peoples, some Western scholars believe that up to 18 million inhabitants lived in what is now known as North America. Upon contact with the European settlers and primarily due to the foreign diseases introduced through them, the American Indian population plummeted to merely 228,000 individuals at the turn to the twentieth century (Sutton, 2008). According to the United States Census (2010a), as of $2010, \mathrm{AI} / \mathrm{ANs}$ made up a mere $0.9 \%$ of the total U.S. population. The total population that identify as AI/AN alone without reporting another race is only 2.9 million (U.S. Census Bureau, 2010a). Another 2.3 million people identify as $\mathrm{AI} / \mathrm{AN}$ in conjunction with at least one other race resulting in a total population of 5.2 million (U.S. Census Bureau, 2010a). This population has seen substantial growth since the 2000 Census and has increased by $39 \%$ in the past 10 years (U.S. Census Bureau, 2012).

The population of focus in this study is located in Arizona where AI/ANs make up 4.6\% of Arizona's total population (U.S. Census Bureau, 2010b) which amounts to 353,386 individuals (U.S. Census Bureau, 2010c). Phoenix, Arizona ranks as the city with the third highest population of AI/ANs in the United States with 43,724 individuals, and Tucson, Arizona ranks as the city with the $11^{\text {th }}$ highest population with 19,903 individuals (U.S. Census Bureau, 2010c). Sutton (2008) reported that due to unemployment rates on reservations, two-thirds of American Indian people now live in cities across the United States and have moved from the established reservations. Despite moving away from their homes, friends, and family to achieve a 
better lives, many of these American Indians living in cities still suffer due to meager housing situations and are unable to receive or afford adequate medical care (Herring, 1994; Sutton, 2008). Perhaps the most detrimental of these losses is the forfeiture of personal and cultural identity (Sutton, 2008).

\section{Theoretical Perspectives}

In this thesis, the researcher focused on the concept of resilience in the at-risk American Indian adolescent population. The researcher looked at this population and their involvement or lack of involvement in school based extracurricular activities through the lenses of Hirschi's (2002) control theory of delinquency and the protective model of resilience. This review of the two theories and of the research literature will suggest that at-risk adolescents' involvement in school based extracurricular activities serve as a buffer against delinquent activity, such as alcohol and substance abuse.

\section{Social Control Theory}

According to Hirschi (2002) delinquency happens as a result of an individual failing to form a connection with society. This failure to bond may happen in four ways: (a) from a lack of attachment to other individuals, (b) a lack of commitment to a group, (c) non-involvement in a group, and/or (d) not being invested with a particular belief system (Hirschi, 2002). First, when an individual fails to bond or form an attachment or hold affection for other individuals and does not understand what is expected of the self in a relationship then they are going to be freer to separate themselves from society's expectations (Hirschi, 2002). Next is the bond of commitment where an individual is traditionally invested an activity such as their education or a profession. A person with a healthy commitment would see that they stand to lose a great investment of their time, energy, or resources if they choose to participate in deviant activities, 
and thus, they refrain from such involvement (Hirschi, 2002). Hirschi (2002) then cites involvement in "conventional" activities (such as sports teams or youth based religious groups) to be the next bond to society that deters delinquency. Finally, when an individual does not internalize a set of beliefs previously adopted by the greater society, they will be less likely to obey these rules and beliefs and more likely to violate those societal standards (Hirschi, 2002).

The bond element of "non-involvement in a group" was focused on in this study and was defined as an individual's involvement in activities and organizations. Hirschi (2002) believed that if an individual was involved in other activities than they would simply not have the time or energy to participate in antisocial behaviors. Also, he thought that adolescents' desires for "recreational" behaviors would have been met through these activities and not through delinquent acts (Hirschi, 2002). The involvement in activities that was assessed in this study was the AI/AN adolescent's involvement in adult-led in-school extracurricular activities including but not limited to participation in an academic club, arts program, or sports team. This population is at-risk for various reasons discussed in a forthcoming section of the paper; these opportunities of being involved in adult-led in-school extracurricular activities could potentially deter acts of delinquency.

\section{Resilience Theory}

Related to Hirshi's (2002) control theory of delinquency is resilience theory which focuses on at-risk individual's positive development despite adverse circumstances. These adultled in-school extracurricular activities could serve the role of a buffer in order to protect the individual from delinquency, and thus instead that individual could experience resilience. The word "resilience" can be defined as the normative development of an individual when they have faced adversity or difficult conditions (Fleming \& Ledogar, 2008). It is important to note that 
resilience is not an aspect of an individual's personality but rather a set of skills they acquire as they face various adverse life circumstances (Blum \& Blum, 2009). Noting that resilience is not an inborn process means that any individual, given the right circumstances, can exhibit resilience (Fleming \& Ledogar, 2008). Adversity, or risk, must be present in order for an individual to show resilience.

One of the most noteworthy resilience studies comes from Werner and Smith (1989) who conducted a longitudinal research study with children prior to birth through young adulthood on the island of Kauai. It was found that despite being raised in disadvantageous family circumstances and withstanding paramount adversity some of these individuals showed a tremendous ability to develop normally (Werner \& Smith, 1989). Interestingly, while an individual may show resilience in one area of their life they may not show resilience in another area (Fleming \& Ledogar, 2008). Resilience happens in context; for example, an individual might be academically resilient but suffer emotionally from risks present in their home and family.

Researchers have developed three basic models of resilience including the compensatory model, protective model, and the challenge model in an attempt to explain under what circumstances resilience may occur (Kretman, Zimmerman, Morrel-Samuels, \& Hudson, 2009). The model of resilience used in this study is the protective model, which states that an individual may experience a lesser negative outcome from experiencing one or multiple risks if there are certain available resources or assets (Fleming \& Ledogar, 2008). Assets that aid positive development of an individual may include their own temperament and other individual characteristics, the family circumstance they find themselves in, and the different environments in which they are involved (Fleming \& Ledogar, 2008). Resources an individual has access to 
may aid in positive development and include, but are not limited to, public services and the quality of education available in the community (Fleming \& Ledogar, 2008). The resources in which this study will focus are the availability and utilization of school based extracurricular activities.

These theories are easily applicable to American Indian adolescents as they are an at-risk population. Extrapolating from social control theory and resilience theory, American Indian adolescents may experiment in delinquent behaviors if they do not form a strong bond with society. Once that bond is established an adolescent may experience resilience in their life as this bond serves as a protective factor against the risk in the individual's environment. Risk factors that could affect the adolescent may include factors inside of the adolescent's home as well as outside the home in the greater community (Waller, Okamoto, Miles, \& Hurdle, 2003). Situations involving risk factors are difficult to escape if an individual does not have access to protective factors which can be available inside or outside of the home, such as a caring relationship with an adult, adequate education, or access to extracurricular activities. In the next section, risk and protective factors are defined and specific risk and protective factors impacting the American Indian adolescent population are reviewed to show their applicability.

\section{Risk and Protective Factors}

\section{Risk Factors}

Throughout history American Indians have been a proud, courageous, and resilient people despite the adversity they have collectively faced. Cumulative impacts of this adversity faced by generation after generation of American Indian people are termed historical trauma (Evans-Campbell, 2008; Goodluck \& Wileto, 2009). Historical trauma is a complex occurrence of traumatic events which has been inflicted upon a group who share a collective identity such as 
religion or race which results in various physical, psychological, and social problems (EvansCampbell, 2008). The impacts of historical trauma can affect the individual person, the family unit, and can reach the community (Evans-Campbell, 2008). Various impacts of trauma on the individual include symptoms of anxiety, depression, unresolved guilt, and posttraumatic stress disorder. These same symptoms an individual experiences then get transmitted between generations in a variety of ways through means of the immediate and extended families and also via the community and in some cases the surrounding environment (Evans-Campbell, 2008). This transmission can happen both directly and indirectly between generations- directly through stories told by elders and indirectly through residual individual effects (Evans-Campbell, 2008). These residual individual effects can be related to emotional suppression and lack of communication in hopes of not transmitting that trauma to the next generation (Evans-Campbell, 2008). From the colonization of the United States to the present day, American Indian people have fought for the land and freedom they believe has always been theirs. The historical trauma discussed will include the dramatic loss of American Indian life (both physical life and cultural life) through contact with European colonizers.

The American Indian population as a whole is more vulnerable than other populations to risk factors due to racism and historical trauma, with one of the subsequent results being high rates of substance abuse (Fleming \& Ledogar, 2008; Herring, 1994). Historically, the American Indian population did not use mind-altering drugs or alcohol recreationally until it was introduced through contact with European colonizers. Prior to contact, such substances were relegated to ceremonial settings (Brave Heart, 2003). Since the time of contact and introduction of alcohol, the American Indian people have struggled with alcohol use and abuse and some researchers attribute that abuse to the loss of cultural traditions and ways of life (Waller et al., 
2003). It is important to note that American Indian adolescents as opposed to adolescents in other populations are more at-risk to experience problems related to drug and alcohol abuse because they are not only influenced by peers in their community but potentially by their parents and additional family members (Waller et al., 2003). Additionally, American Indian families and communities are not likely to stage something resembling an "intervention", as they believe that all individuals need to make their own decisions and choose their own paths (Herring, 1994; Rothbaum \& Trommsdorff, 2007; Waller et al., 2003). This allows for a very natural experience of actions and their consequences but also puts an individual at-risk if they continue to make poor decisions.

American Indian adolescents suffer tremendously as a result of intergenerational problems caused by historical trauma and the problems created by substance use and abuse (Herring, 1994). Substance use and abuse does not only affect an individual's personal health and damage their own body, but can turn into a financial strain on their family as substance abusers seek to finance this habit on an already meager income (Herring, 1994). This can result in an intensification of the family's state of poverty prior to the substance use. American Indian adolescents may not view substance use as a personal choice as alcohol abuse is so normative within their communities (Herring, 1994). Perhaps in these situations adolescents view substance use as a rite of passage into adulthood. In a study conducted by Yu and Stiffman (2007), 401 American Indian urban and reservation youth were interviewed about their substance use and abuse behaviors. The researchers found that adolescents still living on reservation land participated in alcohol use approximately 11 months earlier on average than adolescents not living on reservation land (Yu \& Stiffman, 2007). Twenty percent of the sample population reported consuming alcohol regularly every week and $44 \%$ reported consuming alcohol at least 
once per month (Yu \& Stiffman, 2007). There was a significant difference between reservation and non-reservation youths reports of substance dependency issues, with reservation youth reporting more alcohol dependency issues than non-reservation youth (Yu \& Stiffman, 2007). Participants who identified family alcohol use and abuse along with reporting low socioeconomic status reported more alcohol symptoms than participants from a high socioeconomic status with little family dependency issues (Yu \& Stiffman, 2007).

Alternately, American Indian adolescents also may have protective factors that work to their advantage, such as forms of religious practices and various traditions including language and ceremonies (Fleming \& Ledogar, 2008; Herring, 1994; Yu \& Stiffman, 2007). In the following section protective factors are defined with particular emphasis on protective factors unique to American Indian adolescents. The protective factor of focus for this thesis is the availability of and involvement in adult-led in-school extracurricular activities. Studies concerning this particular protective factor are discussed in more detail later.

\section{Protective Factors}

Waller et al. (2003) explained that for resiliency to occur, risk factors need to be present in an individual's life and the authors described two types of risk factors: adverse circumstances and trauma. When appropriate protective factors are in place in an adolescent's life, than one should expect to see a lower rate of deviance as the protective factor acts as a "buffer" between the adolescent and the risk factor (Waller et al., 2003). Fleming and Ledogar (2008) discussed three important protective factors or "levels" available to individuals including characteristics of individuals themselves, their families, and the local community and organizations in which they are involved. Kretman et al. (2009) cited family as the most important protective factor in an individual's life, regardless of their environment. 
The National Survey on Drug Use and Health (NSDUH, 2004) pointed out protective factors that serve as deterrents to drug and alcohol use by adolescents. In relation to this study, the NSDUH report also found that participation in activities and holding religious beliefs served as protective factors for adolescents. Unfortunately AI/AN adolescents were the least likely ethnic group to participate in activities or to attend religious services (NSDUH, 2004). However, Yu and Stiffman (2007) found that American Indian adolescents who held cultural pride and did claim a religious affiliation were less likely to participate in alcohol abuse or dependence. Gone and Calf Looking (2011), in an article exploring the possibility of culture based interventions for American Indian substance abusers, found that a recommitment to pre-colonial culture could serve as treatment for substance abuse with some individuals. Kretman et al. (2009) discussed how positive school attachment can serve as a protective factor for young children and adolescents as they spend most of their time outside of the home in learning environments and one of the elements most influential in positive school attachment is participation in adult-led extracurricular activities. Relationships with teachers can deter a young person from participating in substance abuse related activities, such as drinking alcohol to the point of being drunk regularly and marijuana usage (Kretman et al., 2009).

It is interesting that Waller et al. (2003) noted that while some assets present in an American Indian adolescent's life might constitute a protective factor, they could also dichotomously turn into a risk factor. For example, an individual's family is close knit, warm, and nurturing; alternately the family may have a high rate of substance abuse among its members and accept the idea of adolescent substance abuse and allow that activity in the home. In the same way, an adolescent might be at-risk if they have a strong family unit they can go to for support but lack support from outside resources such as adult-led extracurricular activities 
(Waller et al., 2003). Additionally these researchers found that family members belonging to the "same generation" as a particular adolescent, both cousins and siblings, could potentially serve as either a risk or a protective factor to the individual (Waller et al., 2003). While a sibling or cousin might stand up for and physically protect an adolescent from negative behaviors such as substance use, the sibling or cousin might also expose the adolescent to substance use or compromising situations where deviance may occur (Waller et al., 2003). Participants in the study conducted by Waller et al. (2003) reported that their ability to abstain from substance use and experimentation was more difficult when they were being pressured to do so by a close family member as opposed to a peer from school.

In summary, American Indian adolescents experience multiple risk and protective factors in their various environments of home and community. In this thesis the protective factor of focus is the effect of adult-led in-school extracurricular activities. As adult-led in-school extracurricular activities could potentially serve a protective role in the life of an adolescent, not having access to those activities could also be detrimental because the adolescent does not have the opportunity to develop a bond with the institution (Silmere \& Stiffman, 2006). In the following section, various studies are reviewed looking at the sample of each study, types of activities studied, and the results of each individual study in regards to substance use and abuse. Findings regarding gender, metropolitan versus non-metropolitan status, and reservation versus non-reservation status are mentioned when relevant to particular studies. Little research has been conducted specifically on American Indian adolescent involvement and the availability of adultled in-school extracurricular activities and the impact these activities have on their substance use and abuse. These AI/AN population specific studies are the last to be reviewed in the following section. 


\section{Adult-Led In-School Extracurricular Activities and Substance Use and Abuse}

Adult-led in-school extracurricular activities of focus in this study include: sports, music, drama, foreign language club, student council/government, newspaper/yearbook, and mentoring or tutoring. If adolescents were involved in another school activity not categorized above then they were able to choose: other school groups or clubs not mentioned in the above choices (AYS, 2010). While team sports are not the exact focal point of this thesis, many existing studies do use team sports as the main activity of attention. Studies, such as Taylor and Turek (2010), focus on sports as a deterrent to delinquent behaviors. In this study, the researchers wanted to examine how involvement in team sports would affect high school African American girls' development of substance use (Taylor \& Turek, 2010). The researchers used a sample of 1,976 girls from both rural and urban areas across the United States. Data for the study was acquired from a large preexisting data set, which limited the researchers' ability to gather specific information regarding duration of involvement in activities, quantity of involvement, and motivation for involvement in team sports. Data collection occurred through two self-report questionnaires. To measure individual and peer substance use, individuals were asked a series of questions separately asking about use of alcohol, marijuana, and illicit drugs and their frequency of use in the last 30 days. Each individual was also asked to self-identify on a six point scale as a non-user of this substance to a heavy user.

These researchers (Taylor \& Turek, 2010) referenced social control theory (Hirschi, 2002) and suggested that through involvement with a prosocial activity such as team sports, African American girls would be less likely to associate with deviant peers and also be less likely to engage in substance use than African American girls not involved in team sports. Results for this study were mixed. Contrary to the researchers' hypothesis, involvement in sports did not 
necessary lead to less substance use by individuals or individual's reports of their peer's use in both rural and urban areas. While substance use by individuals was extremely low for both urban and rural populations and no effects were found with sport participation, the results indicated that these participants living in rural areas reported high peer use of alcohol, marijuana, and illicit drugs. By contrast, urban participants only reported high peer use of alcohol. The researchers suggested that this difference is the result of having a smaller population of peers in rural or nonmetropolitan areas therefore, making it more difficult to consciously choose friends who are not involved in delinquent activities. The researchers also suggest that the "athlete status" is historically linked to substance use and might suggest alcohol use as a normative activity. Also, peers involved in sports might act as an agent of socialization in modeling such alcohol use activity as normative. Adolescents have multiple reasons for participating in organized sports ranging from the activity is a convenient way to spend time with friends to participating in hopes of developing skills that will aid them in earning a college scholarship. The researchers suggested that it is important in future studies to not only ask about if adolescents are involved in an activity, but to also about the frequency of involvement and the individual adolescent's motivation for being involved in the activity (Taylor \& Turek, 2010). The Taylor and Turek (2010) research was reviewed because the study focused on a minority population located in both a metropolitan and non-metropolitan. The following piece of literature was included as frequency of involvement was compared to individual adolescent substance use and abuse.

In a study conducted by Peretti-Watel et al. (2002), the researchers looked at a subsample of a much larger study including 10,807 students age 14-19 in France. Gender differences were also examined by the researchers in their study, and were important to note in this thesis. Participants filled out self-report questionnaires under the supervision of a volunteer, nurse, or 
doctor associated with the survey team. Participants reported on their own individual use of cigarettes, alcohol, and marijuana, then their participation in different types of athletic activities (team sports, athletic sports, strength and combat sports, and individual sports) along with being asked how many hours per week they devoted to athletics. The researchers found that participants' age and gender effected substance use in the results. In particular, they found that boys more often used substances than girls regardless of athletic activity involvement and that as both boys and girls got older, the instances of substance use grew. The researchers found a consistent u-shaped curve of substance use with both genders and types of activities. Participants who did not participate in a sporting activity at all had higher levels of use of cigarettes, alcohol, and marijuana than individuals who were moderately involved in sporting activities. These researchers did find that as participants were involved in sporting activities for 8 or more hours per week their substance reports increased dramatically but rarely exceeded substance use by the non-participants of sporting activities. The researchers found that participants who were involved in club sports had significantly lower rates of all three types of substance use than individuals who did not play on a team but played sports casually with friends or independently. Perhaps this difference is caused by club sports teams being monitored by adult coaches and volunteers (Peretti-Watel et al., 2002). In conclusion, this study supports this thesis in that involvement in adult-led in-school extracurricular activities was related to less use of substances and engagement in risky behaviors.

Cooley et al. (2001) did not focus on the AI/AN population or the three moderating variables included in this thesis; however, they studied student involvement in extracurricular activities along with their involvement with and extent of substance usage. Data were collected from 5,639 participants enrolled in the 5th thru12th grades, in the Midwest. The sample was 
predominantly Caucasian and a majority of the students were from two parent homes. Genders were distributed equally with females representing $51 \%$ of the population, and males representing $49 \%$. The measures were independently developed by the researchers, and included in-depth items concerning drug and substance use. Questions used to determine if participants were or were not involved in extracurricular activities were broken down into three categories: sports, government based clubs such as Student Governance and other clubs, and the arts. Using chi-square analyses, the researchers determined if any relationships existed between certain activities and substance use. Contrary to the hypothesis of this thesis, the authors found that participation in many extracurricular activities only minimally reduced substance experimentation. General findings for substance use and experimentation were lower for participants involved in activities versus those not involved in any activities but the authors were only able to estimate that extracurricular activity involvement does not guarantee an adolescent will not become involved in substance use and abuse, but that it might only lower the amount of experimentation by adolescents (Cooley et al., 2001).

Activity involvement and substance use and abuse were also examined in a research study conducted by Shilts (1991) with 237 eighth grade students in the state of Virginia. The researcher categorized participants in three drug use and abuse categories (i.e., users, abusers, nonusers). The population represented 143 females and 94 males; however, gender was not examined as a variable in their study nor was metropolitan or reservation statuses. Students completed a questionnaire created by the researcher to determine frequencies of drug use and involvement in activities. The researcher predicted that users and abusers who reported less involvement in structured activities spent their free time in nonstructural delinquent activities involving drugs and alcohol with other drug and alcohol using peers. The researcher found that 
the group of students who did not participate in substance use or abuse reported being actively involved in school extracurricular activities (Shilts, 1991). To conclude, Shilts (1991) study reinforces that involvement in adult-led in-school extracurricular activities is related to less engagement of substances.

Regarding substance use and activities, Duncan, Duncan, Strycker, and Chaumeton (2002) conducted a study in the Pacific Northwest with a sample of 356 adolescents aging between 10 and 14 years old concerning the relationship of prosocial to antisocial activities. In this research study prosocial activities were described as sports, non-sport activities, and religious/volunteer opportunities. Antisocial activities were identified as lying, stealing, and different types of substance use: cigarettes, alcohol consumption, and marijuana usage. The sample was primarily Caucasian adolescents (73\%) with the remaining sample consisting of African American (12\%), Hispanic (4\%), Asian (2\%), American Indian (2\%), and Other (7\%) adolescents. Gender was equally distributed; gender and age were examined in multiple subgroups of 10,12, and 14 year old boys and girls. Respondents completed a self-report survey as the method for data collection which included questions about prosocial and antisocial activities, which include some of the dependent variables of this thesis. Answers were reported on a 5-point scale. Significant relations were found between sport team involvement and prosocial activities across all age groups. In regard to substance use, the 14 year old groups both reported significantly higher substance use as opposed to the 10 and 12 year old groups. In most of the groups, substance use and deviance were positively associated with one another. One aspect of the study which yielded significant results was family income in relation to prosocial activity which brought to light the issue that adolescents in more financially secure homes and communities might have more opportunities for becoming involved in extracurricular activities 
as opposed to adolescents coming from single parent or financially disadvantaged homes and communities such as a minority population like AI/AN or reservation communities (Duncan et al., 2002).

Gender was a major component of a study conducted by Elder et al. (2000) with 3,556 10th through 12th grade students in the southeastern United States. The researchers hypothesized that involvement in activities would be related to less use of cigarettes, alcohol, and marijuana. This large sample represented genders equally but was primarily Caucasian with less than $20 \%$ of the population identifying as African American or other. The researchers used measures of the Adolescent Health Survey, Alabama Adolescent Survey and the Youth Risk Behavior Survey to determine the level of extracurricular involvement and instance of cigarette, marijuana, or alcohol use. The researchers found that male students were more likely to report smoking cigarettes, drinking alcohol, and smoking marijuana than female students. The researchers found that moderate participation in extracurricular activities inside and outside of the school served as a protective factor against cigarette, marijuana, and alcohol use. Interestingly the researchers found that high extracurricular involvement, reported as being involved in more than two activities per week, did not serve to be more protective against the use of substances than those of moderate involvement in activities. The authors discussed that future research should be done concerning this finding and suggest that over-involvement in activities could create stress in an adolescent's life and they may seek refuge in substance use (Elder et al., 2000). To summarize, the researchers hypothesis was supported and involvement in activities was found to be related to less engagement of substances.

Eccles and Barber (1999) examined the relationship of different types of adult-led sponsored activities and adolescents' experimentation and use of substances. The five types of 
activities assessed were prosocial types of activities (such as volunteering or religious

participation), sports, school involvement activities (such as school government), the performing arts, and academic clubs. The researchers hypothesized that involvement in these activities would result in less delinquent behaviors such as substance use. The researchers suggested that when adolescents fill their schedule with positive activities they will have less free time to get involved in delinquent activities and will also give them an opportunity to learn new skills and develop new relationships. The sample for this research study came from existing data from a longitudinal study of students in southeast Michigan. Participants numbered 1,259 adolescents and no specific demographics were given except that the population was primarily Caucasian and middle-class. Data was collected in the form of self-report questionnaires. Components of the questionnaire included an area where students could number the types of activities they were involved in, reported their risk taking behaviors including alcohol and drug use on a seven point scale, and their personal academic attitudes on a seven point scale. Data concerning their mother's level of education was obtained during the first wave of data collection during the informed consent process. Participants' delinquent activity records were obtained through the school system.

Interestingly, $31 \%$ of the students surveyed did not participate in any activity at all (Eccles \& Barber, 1999). The number one activity for students of both genders to be involved in was school team sports. In regard to involvement in team sports, the researchers found that participation in these activities did relate to an increase in the use of alcohol. On the other hand, the researchers found that adolescents who were involved in the performing arts (band, dance, orchestra, etc.) engaged in delinquent behaviors including substance abuse less frequently than those who were not involved in adult-led sponsored activities. The researchers also found that 
involvement in school activities (example, school government) was not related to engagement in delinquent activities including substance use. Of those students who were involved in prosocial activities (i.e., volunteering, religious activities), they were least likely to use substances longitudinally than other participants involved in other or no activities at all. The authors suggested that prosocial sponsored activities can be a protective mechanism regardless of an adolescent's age. In regards to gender, the researchers found that for males participation in the performing arts, lower grade level, and participation in prosocial activities were all related to lesser levels of drug and alcohol use. All five categories of extracurricular activities were related to more enjoyment of school, higher grades, and adolescents who were involved in sponsored activities were more likely to attend college than adolescents who were not involved (Eccles \& Barber, 1999).

To summarize the articles reviewed in regard to adult-led in-school extracurricular activities acting as a deterrent to substance use for various sample populations, previous studies have shown mixed results. Taylor and Turek (2010) found that substance use among girls involved in activities in their study was low, but found that participants in rural areas reported high peer use of substances. The Peretti-Watel et al. (2002) study found that age and gender affected substance use in their sample, as well as no participation in a sporting activity. The researchers also found that participants of club sports reported significantly lower rates of substance use than participants who reported playing sports with friends and were not part of a team (Peretti-Watel et al., 2002). Contrary to the hypothesis of this thesis, Cooley et al. (2001) found that participation in activities only reduced substance experimentation minimally and did not guarantee that an adolescent would not become involved in substance use and abuse. Shilts (1991) on the other hand found that participants who reported no participation with substance use 
and abuse reported being actively involved in activities. Next, Duncan et al. (2002) found that higher age groups reported more frequent substance use and abuse as opposed to younger age groups. Elder et al. (2000) reported that participation in activities in their study was found to be protective against substance use and abuse. Finally, Eccles and Barber (1999) found that involvement in team sports among participants was related to an increase in the use of alcohol. However the researchers also found that participants involved in the performing arts used substances less frequently than those who were not involved in any activity at all. Further, those involved in prosocial activities were least likely to use substances longitudinally of all participants. It is important to note that research regarding substance use, adult-led in-school extracurricular activities, and the AI/AN adolescent population is limited. Two research studies are conducted with AI/AN youth specifically that were reviewed in the following paragraphs.

Stiffman et al. (2007) conducted a study among 401 American Indian youth living on reservations and urban areas in the Southwest and examined the relationships of individual, family, and community strengths relative to individual outcomes including substance use. One methodological flaw of this study is that the researchers did not address that both reservation and non-reservation areas can have urban areas, nor do they define what constitutes an urban area. The researchers conducted this study because few researchers are examining environmental strengths or American Indian adolescents' perceptions of their strengths, including adult-led inschool extracurricular activities. First, participants were interviewed with parents present to obtain participant and guardian consent. The 401 participants of this study were then picked at random from the original consenting group and asked to complete an open-ended strengths measurement concerning themselves, their family, and their community, and then structured measurements on personal strengths, family strengths, several aspects of community strengths 
(school, neighborhood, and peer), and finally on personal problems, which included questions concerning delinquency and substance abuse issues. On every level with the exception of "tribal strengths", urban youth listed more strengths and positive aspects to themselves, their family, and their community than participants living on reservation lands. In regard to their school strengths, participants listed clubs and sports as the top two strengths about their schools. Reservation adolescents were twice as likely to report that there were "no strengths" in regard to their schools. The authors found a moderate negative correlation between the self-reported number of school strengths (including opportunity to be involved in adult-led in-school extracurricular activities) and an individual youth's alcohol and substance symptoms (Stiffman et al., 2007). In conclusion, this study revealed that with more strengths these American Indian adolescents perceived their schools to have, including adult-led in-school extracurricular activities, less reports of substance use and abuse were made.

While tobacco use is not a variable in this study, it is important to note research conducted by Osilla et al. (2007) with the AI/AN population because it is focused on a substance and gender differences were examined. The researchers conducted this study in Seattle, Washington with $\mathrm{AI} / \mathrm{AN}$ adolescents to look at protective factors (i.e., extracurricular activities) in place that might decrease the instance of regular use of tobacco. Participants who identified themselves as AI/AN were recruited through public schools and also a local outpatient clinic to participate in eight intervention sessions. The data for this study is the result of an interview where participants reported on their peer groups and their own, education plans, participation in team sports, playing music, and volunteer activities. Participants also reported on their own tobacco use including questions such as their age of first tobacco experience, age of first regular use, and if they currently used tobacco regularly at the time of the study. Ages of participants 
ranged from 13 to 19 years old, included 112 total participants $53 \%$ of which were female, and represented 40 tribes. In this population, $58 \%$ of the adolescents reported using tobacco products in their lifetime and the average age of first use was 10.38 years old. Average age for regular use of tobacco products was 12.67 years old. Almost half of the population (45\%) reported current regular tobacco use and more females than males reported current regular tobacco use. The three key protective factors related to less engagement of substances as reported by this population in the study were college aspirations, participation in team sports, and participation in playing music. The researchers suggested that these American Indian adolescents were involved in structured free time activities after school and these activities were key in protecting them against current regular use of tobacco (Osilla et al., 2007).

Summarizing across these two studies, Stiffman et al. (2007) conducted research on 401 American Indian youth in the categories of "urban" and "reservation." The researchers found that urban adolescents reported higher strengths as opposed to reservation youth in every area other than "tribal strengths." Reservation adolescents were then twice as likely as urban participants to report their school having "no strengths," which would include adult-led in-school extracurricular activities offered by individuals' schools. The researchers also found a moderate negative correlation between number of reported school strengths and the adolescents' reported alcohol and substance symptoms. In the study conducted by Osilla et al. (2007) the researchers suggested that being involved in structured activities (such as extracurricular activities) is protective from use and abuse of tobacco. Osilla et al. (2007) studied tobacco which is not one of the dependent variables of focus for this thesis, however little research is available on American Indian adolescents' use of substances in regard to involvement in adult-led in-school extracurricular activities. This thesis fills that gap in research. The following paragraphs discuss 
the moderating variables of gender, reservation versus non-reservation status, and metropolitan versus non-metropolitan status in respect to existing literature on adolescent involvement in adult-led in-school extracurricular activities on their substance use and abuse behaviors.

The literature has established significant relations between extracurricular activities and substance use and abuse of adolescents. Of additional importance is how other variables can moderate these relations. Aside from moderation, gender differences have been noted in extracurricular involvement and in use of substances. Some studies reported gender differences in regard to extracurricular activity involvement. Peretti-Watel et al. (2002) found that adolescent males in their study were more involved in activities as a whole than females. However, according to Eccles and Barber (1999) females were found to participate in activities more often than males. Also, females were found to participate in a wider variety of activities as opposed to males (Eccles \& Barber, 1999). In regard to gender, extracurricular activity involvement, and substance abuse, Peretti-Watel et al. (2002) found that regardless of activity level males reported using substances more than females. Similarly, Elder et al. (2000) found that males were more likely to report using cigarettes, alcohol, and marijuana than female students. Tobacco use is not a dependent variable in this study but little research is conducted on strictly the AI/AN population so it is interesting to note that in a study conducted by Osilla et al. (2007), with $\mathrm{AI} / \mathrm{AN}$ adolescents the researchers found that more females as opposed to males reported current regular use of tobacco than males. Duncan et al. (2002) found that regardless of gender, substance use was reported more significantly in association with older age of adolescents. In this study, gender was looked at as a moderating variable due to its importance in previous studies regarding adult-led in-school extracurricular activities in association with adolescent substance use and abuse. In regard to moderation in previous studies, Eccles and Barber (1999) 
found that for males, participation in the performing arts, prosocial activities, along with lower grade level were all associated with lower levels of reported drug and alcohol usage.

In addition to gender, reservation versus non-reservation status along with metropolitan versus non-metropolitan status were tested as moderators in this thesis. Reservation land lies in both metropolitan and non-metropolitan areas of the state of Arizona. Therefore, it is important to include both variables (i.e. reservation versus non-reservation status and metropolitan versus non-metropolitan status) for this population in terms of the focus of this study. Taylor and Turek (2010) also examined substance use by a minority population in what they termed "rural and urban" areas and found that adolescents living in rural or non-metropolitan areas reported high peer pressure to use alcohol, marijuana, and illicit drugs as opposed to urban or metropolitan adolescents who reported high peer pressure to use alcohol only. Stiffman et al. (2007), found that adolescents living in off reservation urban areas listed more strengths in themselves and in their school than reservation adolescents. Twice as many reservation as urban adolescents reported their school had no strengths whatsoever. These strengths were moderately negatively correlated with an individual's alcohol and substance symptoms of use and abuse (Stiffman, et al., 2007). However, one issue with the study conducted by Stiffman et al. (2007) is that the labels used were "reservation" and "urban." The authors did not specify that the reservations were rural or urban nor did they mention if the urban areas included any reservation land. It is surprising that so few studies have examined reservation and metropolitan living statuses for American Indian adolescents. Therefore, the present study will fill a gap in the literature in these respects.

In summary, researchers have found that adolescent involvement in adult-led in-school extracurricular activities has shown to be beneficial in many populations, including American 
Indian adolescents. Specifically, research has shown that adolescents who are involved in adultled in-school extracurricular activities experiment and use various substances less often than adolescents who are not involved in these activities (Shilts, 1999; Elder et al., 2000; PerettiWatel et al., 2002). Little research has been conducted explicitly with the American Indian adolescent population in regard to their availability of and involvement in adult-led in-school extracurricular activities and the effect that involvement may have on adolescent use and abuse of substances. The first hypothesis of this thesis is that availability of adult-led in-school extracurricular activities will be related to lower substance usage and less engagement in risky substance abuse behaviors (see Figure 1). The second hypothesis of this thesis is that greater involvement (defined as frequency of participation and number of activities) in adult-led inschool extracurricular activities will be related to lower substance usage and less engagement in risky substance abuse behaviors (see Figure 2). Gender, reservation versus non-reservation status, and metropolitan versus non-metropolitan status were examined in these hypotheses. 


\section{Chapter 3}

\section{Methods}

\section{Overview of Research Design}

For this thesis a quantitative research design was used. Students attending Arizona middle schools and high schools who self-identified as AI/ANs comprised the sample.

Independent variables for this thesis include the availability of adult-led in-school extracurricular activities as well as the individual student's involvement in adult-led in-school extracurricular activities based on the frequency of participation and on the total number of activities in which they are involved. Dependent variables in this study included the use of alcohol, marijuana, illicit drugs, prescription drugs, and over the counter drugs by the student as well as their engagement in risky substance abuse activities including being drunk or high at school, riding with a drunk driver or driving drunk themselves, or selling drugs. Gender, metropolitan versus nonmetropolitan status, and reservation versus non-reservation status were examined in these hypotheses as potential moderating variables (see Figures 1 and 2).

\section{Sample}

The Arizona Youth Survey (AYS) was administered from January to May 2010 in every county in the state to a total of 372 individual schools and was completed by $63,7848^{\text {th }}, 10^{\text {th }}$, and $12^{\text {th }}$ grade students from various ethnicities/races (AYS, 2010). The sample for this study consisted of $5,7018^{\text {th }}(46.2 \%), 10^{\text {th }}(31.8 \%)$, and $12^{\text {th }}(22 \%)$ grade AI/AN students who participated in the 2010 AYS (Table 1). Item 4 allowed participants to mark as many races as applied to them resulting in $68 \%$ identifying as solely AI/AN and the remaining $32 \%$ identifying as AI/AN and one or more other ethnicities (see Table 1). Of this sample, only 5,475 answered item 5 regarding Hispanic or Latino ancestry, resulting in $33.2 \%$ identifying as Hispanic or 
Latino out of that number rather than the full sample (see Table 1). Specific tribal affiliations were not obtained. Gender, age, grade, and race were self-reported by each participant (see Appendix A). Of the participants, 50.9\% were male with the remaining $49.1 \%$ female. As an indicator of SES, the total percentage of students receiving either free or reduced cost lunch was $62.7 \%$ with the remaining $37.3 \%$ not receiving any assistance.

The participants' zip codes were obtained from the self-report demographics section of the AYS and were coded to determine if a participant was living on or off a reservation and whether they were considered living in a metropolitan or nonmetropolitan area (see Appendix A). Zip codes were taken from the first page of the self-report questionnaire and coded based on information from tribal websites outlining zip codes for reservation land. The United States Postal Service website (http://www.usps.com) and a zip code search engine website titled "Brainy Zip" (http://www.brainyzip.com) were used to determine what zip codes constituted reservation or non-reservation status. Participants living on reservation land were coded as 1 , participants living off reservation lands were coded with a 0 . Participants living on reservation lands made up $28.9 \%$ of the total sample population with the remaining $71.1 \%$ reported living off of reservation land. Metropolitan status was defined by the US Census Bureau (2010) as an area consisting of 50,000 or more people. Again, using the zip codes from the first page of the self-report questionnaire, the zip codes were compared to a list provided by the US Census Bureau (2010) outlining what cities were included in the metropolitan areas in Arizona and the other resources previously listed. Participants living in metropolitan areas were coded as 1 ; participants living outside of metropolitan areas were coded with a 0 . Participants living in metropolitan areas made up $45.9 \%$ of the total sample population with the remaining $54.1 \%$ living outside of metropolitan areas. 


\section{Procedures}

Each school sent home a letter containing important information regarding the Arizona Youth Survey with a web-address linking to the actual survey for parents to review the questions and topics on which their children would report (see Appendix B for a sample letter). There was a place on the paper for parents to sign and return the form if they wished for their child to not participate in the study. Students not participating in the study were those whose parents had signed and returned the form or those who expressed they did not wish to take part in the survey. Students were allotted one full class period to fill out the survey. At the beginning of the class period each teacher read a prepared statement from the AYS team reminding students that participation was voluntary and if they did want to participate they did not have to, and could also skip answering any questions that they did not feel comfortable answering. Teachers were given written instruction, surveys, and a written statement to read at the beginning of the data collection; no training was necessary. Data collection occurred in individual classrooms and was administered by the students' teachers without the presence of a researcher in the classroom. Anonymity and confidentiality was assured to participants and their parents in the letter previously sent home by the schools as well as verbally assured by the statement read by the teacher at the beginning of the data collection class period. This same statement was also printed as part of the instructions of each survey. Each school completed data collection on a specified day between January and May 2010 in 372 schools across the state including schools in all 15 counties of the state.

\section{Instrumentation}

The instrument used for the AYS was a questionnaire developed with funding from the Center for Substance Abuse Prevention to measure specific risk and protective levels in 
adolescent lives. It was a collaborative project of six states through the University of Washington. The protective areas the Arizona Youth Survey is concerned with are evaluating an adolescent's community, their school, their family, and their peer group. In the original survey, respondents answered 319 individual questions on the questionnaire. All of these measures were on a self-report questionnaire where individuals were also asked to report demographic information including gender, race, and zip code. This thesis examines 23 of the original number of questions and their responses. Only items used in this study are included in the copy of the survey included in Appendix A. It should be noted that in Appendix A, these items are grouped into the variable categories and include the original items with numbering from the Arizona Youth Survey (2010). The variables are grouped into three major categories as shown in the following paragraphs; a more clear depiction of how the variables were categorized can be found in Table 2.

Frequency of substance use. Substance use of adolescents was examined in 5 separate substance categories: alcohol, marijuana, illicit drugs, pharmaceutical drugs, and over the counter drugs (Table 2).

Alcohol and marijuana were each examined as individual dependent variables (AYS items 50 and 52, repectively). LSD/hallucinogens, cocaine, inhalants, phenoxydine, methamphetamines, heroin/opiates, ecstasy and steroids were examined in a combined category hereby referred to as illicit drugs (AYS items of 54, 56, 58, 60, 62, 64, 66, and 68). Cronbach's alpha for illicit drugs was .49. Prescription pain relievers, prescription stimulants, and prescription sedatives were in a combined category hereby referred to as pharmaceutical drugs (AYS items of 70,72, and 74). Cronbach's alpha for the pharmaceutical drug category was .61. Over the counter drugs were examined not in combination with any other variable (item 76). For 
each of these substance categories the participants were to report on a 7-point scale ranging from zero to 40 or more how many times in the past 30 days they had used each individual substance (see Appendix A).

Risky substance use behaviors. In addition to the substance use questions, participants also answered questions based on their risky substance abuse activities which were examined in three additional variables (Table 2). The item referred to as "ride or drive" drunk which meant reported riding with an intoxicated individual or driving themselves while intoxicated was a combined category (AYS items of 34 and 35). Item 34 asked participants to report on a fivepoint scale ranging from 0 to 6 or more times according to how many times in the past 30 days they had ridden in a vehicle where the driver had been drinking alcohol, then were asked again on item 35 to report on the same five-point scale how many times they themselves had driven when they had been drinking alcohol. The Cronbach's alpha for these two collapsed items was .59.

The second risky substance use behavior question examined participants selling illegal drugs at school. Participants were asked on items 30(c) to answer on an eight-point scale ranging from never to 40 or more times in the past year that they had sold illegal drugs at school. Item 30 (i) represented the third question of risky substance abuse behaviors, having been drunk or high at school, and participants responded on an eight point scale mirroring the scale for item 30 (c).

Extracurricular availability and frequency of participation. The protective areas of focus for this study were availability of adult-led in-school extracurricular activities at participants' schools and adolescents' participation in adult-led in-school extracurricular activities. Three aspects of extracurricular activities were assessed. Regarding activity availability, item 11 asked adolescents to report their perceptions on whether extracurricular 
activities were available at their school. Adolescents respond on a four point scale ranging from emphatic NO!, No, Yes, and finally to an emphatic YES!

Regarding frequency of participation, the participants were asked on item 30(e) how often in the past year they had participated in these extracurricular activities at school. Answers range on an eight-point scale from never to 40 times or more. Also for hypothesis two, the total number of activities the participant chose on item 108 determined the total number of activities the participant was involved in for the independent variable (see Appendix A). 


\section{Chapter 4}

\section{Results}

\section{Preliminary Analyses}

Correlations and $t$-tests were run as preliminary analyses prior to three sets of eight regressions. Nearly all correlations were significant, but this point should be taken with a note of caution due to the large sample size. Table 3 shows significance according to the statistical test; however, for interpretation purposes, a different demarcation of significance was applied. Correlations which accounted for $10 \%$ or more of the variance or where $r>.33(+$ or -$)$ were considered significant. It is interesting to note that reported alcohol and marijuana use were significantly positively correlated with each other and also with all three risky behavior items at $\mathrm{p}>.33$ (see Table 3). It was also interesting to see that prescription drugs and OTC drugs were significantly positively correlated with one another at $\mathrm{p}>.33$ (see Table 3 ).

Significant $t$-tests for gender included activities frequency, $t(5500)=-3.61, p=.00$, number of activities $t(4895)=-6.00, p=.00$, marijuana, $t(5280)=3.61, p=.00$, OTC drugs, $t$ $(5271)=-2.79, p=.01$, and selling drugs $t(5484)=7.95, p=.00$ (see Table 4$)$. Females $(M=$ $3.12, S D=2.11)$ were more frequently involved in activities than males $(M=2.91, S D=2.20)$, and females $(M=1.12, S D=1.18)$ were involved in more total number of activities than males $(M=.93, S D=1.18)$. On scales of substance use, males $(M=1.70, S D=1.61)$ reported using more marijuana than females $(M=1.56, S D=1.34)$, and males $(M=1.44, S D=1.34)$ reported selling drugs more than females $(M=1.22, S D=.84)$. Females $(M=1.16, S D=.67)$ reported using more OTC drugs than males $(M=1.12, S D=.53)$.

Results regarding $t$-tests for metropolitan versus non-metropolitan status yielded one significant result for reports of being drunk or high at school, $t(5498)=2.46, p=.01$ (see Table 
5). Specifically, non-metropolitan $(M=1.84, S D=1.69)$ adolescents reported being drunk or high at school more than metropolitan $(M=1.73, S D=1.66)$ adolescents. Significant $t$-tests for reservation versus non-reservation status included activities availability, $t(5620)=2.40, p=.02$, frequency of activities, $t(5583)=2.37, p=.02$, marijuana, $t(5357)=-4.69, p=.00$, prescription drugs, $t(5357)=2.19, p=.03$, OTC drugs, $t(5349)=2.06, p=.04$, drunk or high at school, $t$ $(5588)=-6.08, p=.00$, and riding or driving while drunk, $t(5523)=-3.17, p=.00$ (see Table 6). In regard to activities, non-reservation $(M=3.28, S D=.80)$ adolescents reported more activities were available to them than reservation $(M=3.22, S D=.80)$ adolescents. Non-reservation $(M=$ 3.05, $S D=2.21)$ adolescents also were more frequently involved in activities than reservation $(M$ $=2.90, S D=2.01)$ adolescents. In regard to substance use, reservation $(M=1.78, S D=1.58)$ adolescents reported using marijuana more than non-reservation $(M=1.57, S D=1.44)$ adolescents. Non-reservation $(M=1.11, S D=.41)$ adolescents reported more prescription drug use than reservation $(M=1.09, S D=.34)$ adolescents. Non-reservation $(M=1.15, S D=.63)$ adolescents also reported more over-the-counter drug use than reservation $(M=1.11, S D=.85)$ adolescents. In regard to risky behaviors, reservation $(M=2.00, S D=.85)$ adolescents reported being drunk or high at school more than non-reservation $(M=1.70, S D=1.63)$ adolescents; also reservation $(M=1.51, S D=.85)$ adolescents reported riding or driving drunk more than nonreservation $(M=1.44, S D=.80)$ adolescents.

\section{Primary Analyses}

For this thesis, three sets of eight regressions were run. The dependent variables for each regression were reported alcohol use, marijuana use, illicit drug use, prescription drug use, over the counter drug use, being drunk or high at school, riding with an intoxicated driver or driving a car while intoxicated, and selling drugs. The first set of regressions concerned the availability of 
adult-led in-school extracurricular activities and examined potential interactions between availability and gender, metropolitan versus non-metropolitan status, and reservation versus nonreservation status (see Table 7). The second set of regressions concerned reported frequency of involvement in adult-led in-school extracurricular activities and examined potential interactions between frequency of involvement and gender, metropolitan versus non-metropolitan status, and reservation versus non-reservation status (see Table 8). The final set of regressions concerned the reported number of adult-led in-school extracurricular activities adolescents were involved in and examined potential interactions between number of activities and gender, metropolitan versus non-metropolitan status, and reservation versus non-reservation status (see Table 9). Results are shown in the tables for other demographic variables but only significant findings related to adult-led in-school extracurricular activities and their interactions with the three moderating variables are discussed in the following sections.

\section{Primary Analyses: Availability}

Alcohol. One significant interaction was found for alcohol and availability along with metropolitan status, $F(9,5125)=20.80, p<.001, R^{2}=.03$ (see Figure 3). Specifically, those who live in metropolitan areas with little availability of activities reported more alcohol use than adolescents living in metropolitan areas who had more activities available to them.

Marijuana. There were two interactions found for marijuana and availability of adult-led in-school extracurricular activities. The first was availability of activities with gender, $F(9$, $5067)=25.38, p<.001, R^{2}=.04$ (see Figure 4). Specifically, males were more likely to report marijuana use when few activities were available to them. The next interaction was the availability of activities and metropolitan versus non-metropolitan status, $F(9,5067)=25.38, p$ $<.001, R^{2}=.04$. (see Figure 5). Specifically, those living in metropolitan areas reported more 
marijuana use when few activities were available to them and less use when more activities were available to them.

Illicit drugs. There were no significant findings for illicit drug use relative to availability of activities and any of the interactions between availability of activities with sex, reservation versus non-reservation status, or metropolitan versus non-metropolitan status.

Prescription drugs. For prescription drug use there was one significant interaction found between availability of activities and gender, $F(9,5066)=6.83, p<.001, R^{2}=.01$ (see Figure 6). Specifically, males were more likely to report prescription drug use when there were fewer activities available to them and less likely to report prescription drug use when many activities were available.

Over the counter drugs. The only significant finding regarding over the counter drug use was a main effect finding for the availability of adult-led in-school extracurricular activities, $F(9,5058)=4.26, p<.001, R^{2}=.006$. Specifically, those who had activities available to them were less likely to use over the counter drugs. There were no significant interactions found for sex, reservation versus non-reservation status, and metropolitan versus non-metropolitan status.

Drunk/high at school. The first interaction was availability and metropolitan versus nonmetropolitan status, $F=(9,5281)=20.56, p<.001, R^{2}=.03$ (see Figure 7). Specifically, those who lived in a metropolitan area reported more instances of being drunk or high at school when fewer activities were available to them and fewer instances when many activities were available to them.

Ride/drive drunk. There were no significant findings for ride/drive drunk relative to availability of activities for any of the interactions between availability of activities and sex, reservation versus non-reservation status, or metropolitan versus non-metropolitan status. 
Selling drugs. The first interaction found for selling drugs was activity availability and gender, $F(9,5268)=17.68, p<.001, R^{2}=.02$ (see Figure 8 ). Specifically, males reported significantly more instances of selling drugs when fewer activities were available to them than when more activities were available to them. The second interaction for selling drugs was between availability of activities and metropolitan versus non-metropolitan status, $F(9,5268)=$ $17.68, p<.001, R^{2}=.02$ (see Figure 9). Specifically, adolescents living in metropolitan areas who reported little availability of activities reported higher frequency of selling drugs than those who had many activities available to them.

\section{Primary Analyses: Frequency}

The second set of regressions concerned the reported frequency of involvement in adultled in-school extracurricular activities. Potential interactions between frequency of activity and gender, reservation versus non-reservation status, and metropolitan versus non-metropolitan status were tested (see Table 8).

Alcohol. The only significant interaction for alcohol was with frequency of involvement and reservation status, $F(9,5131)=18.55, p<.001, R^{2}=.03$ (see Figure 10). Specifically, those living on a reservation reported more alcohol use when they were participating in activities less frequently whereas those living on reservation land who reported more frequent activity involvement reported much lower alcohol usage.

Marijuana. There was a main effect found for frequency of involvement in adult-led inschool extracurricular activities and marijuana use, $F(9,5073)=28.72, p<.001, R^{2}=$ .04.Specifically, those who were involved in activities more frequently were less likely to use marijuana. There were two interactions found for marijuana use and frequency of involvement. The first interaction found for marijuana use was the frequency of involvement and reservation 
versus non-reservation status, $F(9,5073)=28.72, p<.001, R^{2}=.04$ (see Figure 11$)$.

Specifically those living on reservation land reported more marijuana use when they were participating in activities less frequently whereas those living on reservation land who reported more frequent activity involvement reported much lower marijuana usage. The second interaction found regarding marijuana use was the frequency of involvement and metropolitan versus non-metropolitan status, $F(9,5073)=28.72, p<.001, R^{2}=.04$ (see Figure 12). Specifically, those living in metropolitan areas who reported they were participating in activities less frequently reported higher usage than those living in metropolitan areas who reported frequent activity participation.

Illicit drugs. There were no significant findings for illicit drug use relative to frequency of involvement for any of the interactions between frequency of involvement and sex, reservation versus non-reservation status, or metropolitan versus non-metropolitan status.

Prescription drugs. There were no significant findings for prescription drug use relative to frequency of involvement in activities for any of the interactions between frequency of involvement and sex, reservation versus non-reservation status, or metropolitan versus nonmetropolitan status.

Over the counter drugs. There were no significant findings for over the counter drug use relative to frequency of involvement in activities for any of the interactions between frequency of involvement and sex, reservation versus non-reservation status, or metropolitan versus non-metropolitan status.

Drunk/high at school. There were two interactions regarding frequency of activity involvement and reports of being drunk or high at school. The first interaction regarded frequency of involvement in activities, being drunk or high at school, and reservation versus non- 
reservation status, $F(9,5281)=20.56, p<.001, R^{2}=.001$. (see Figure 13). Specifically, those living on reservation lands who were less frequently involved in activities reported more instances of being drunk or high at school whereas those reporting being more frequently involved in activities reported fewer instances of being drunk or high at school. The next interaction regarding reports of being drunk or high at school involved frequency of activity involvement and metropolitan versus non-metropolitan status, $F(9,5281)=20.56, p<.001, R^{2}=$ .001. (see Figure 14). Specifically, those living in metropolitan areas who reported less frequent involvement in activities reported more instances of being drunk or high at school whereas those who reported more frequent involvement reported fewer instances of being drunk or high at school.

Ride/drive drunk. There were three interactions found for reports of riding with an intoxicated person or driving intoxicated with frequency of involvement. The first interaction regarding riding with an intoxicated person or driving while intoxicated was frequency of involvement and gender, $F(9,5221)=7.86, p<.001, R^{2}=.01$ (see Figure 15). Specifically, females who reported less frequent involvement in activities reported higher instances of riding with an intoxicated individual or driving a vehicle while intoxicated whereas males were more likely to report riding with an intoxicated individual or driving a vehicle while intoxicated when they were involved in activities more frequently. The second interaction was frequency of involvement and reservation versus non-reservation status, $F(9,5221)=7.86, p<.001, R^{2}=.01$ (see Figure 16). Specifically, those living on reservation lands were more likely to report riding with an intoxicated driver or driving a vehicle while intoxicated when they were less frequently involved in activities and also less likely to ride with an intoxicated individual or drive a car while intoxicated when they were involved in activities more frequently. The third interaction 
was frequency of involvement and metropolitan versus non-metropolitan status, $F(9,5221)=$ $7.86, p<.001, R^{2}=.01$ (see Figure 17). Specifically, those living in metropolitan areas who reported less frequent involvement in activities reported more instances of riding with an intoxicated individual or driving a vehicle while intoxicated than those in a metropolitan area who reported more frequent involvement in activities.

Selling drugs. There was only one significant interaction between frequency of involvement in activities and selling drugs which was metropolitan versus non-metropolitan status, $F(9,5268)=17.68, p<.001, R^{2}=.02$ (see Figure 18). Specifically, those who live in metropolitan areas who reported less frequent activity involvement reported more instances of selling drugs as opposed to those in metropolitan areas who were more frequently involved in activities.

\section{Primary Analyses: Number of Activities}

The third and final set of regressions reported the number of adult-led in-school extracurricular activities adolescents were involved in. Potential interactions between number of activities and gender, reservation versus non-reservation status, and metropolitan versus nonmetropolitan status were observed (see Table 9).

Alcohol. There were no significant findings for alcohol use relative to number of activities nor for any of the interactions between number of activities with sex, reservation versus non-reservation status, or metropolitan versus non-metropolitan status.

Marijuana. There were no significant findings for marijuana use relative to number of activities nor for any of the interactions between number of activities with sex, reservation versus non-reservation status, or metropolitan versus non-metropolitan status.

Illicit drugs. There were no significant findings for illicit drug use relative to the number 
of activities nor for any of the interactions between number of activities and sex, reservation versus non-reservation status, or metropolitan versus non-metropolitan status.

Prescription drugs. There were no significant findings for prescription drug use relative to the number of activities nor for any of the interactions between number of activities and sex, reservation versus non-reservation status, or metropolitan versus non-metropolitan status.

Over the counter drugs. There were no significant findings for over the counter drug use relative to the number of activities nor for any of the interactions between number of activities and sex, reservation versus non-reservation status, or metropolitan versus nonmetropolitan status.

Drunk/high at school. Number of activities was a predictor of being drunk or high at school, $F(9,4693)=14.8, p<.001, R^{2}=.02$. Specifically, those involved in more activities were less likely to be drunk or high at school.

Ride/drive drunk. There were no significant findings for reports of riding with an intoxicated driver or driving intoxicated themselves relative to the number of activities nor for any of the interactions between number of activities and sex, reservation versus non-reservation status, or metropolitan versus non-metropolitan status.

Selling drugs. The only interaction found between number of adult-led in-school activities adolescents reported being involved in and selling drugs was with metropolitan versus non metropolitan status, $F(9,4693)=13.18, p<.001, R^{2}=.02$ (see Figure 19). Specifically, adolescents in metropolitan areas who reported fewer numbers of activities they were involved in reported more instances of selling drugs as opposed to adolescents who lived in metropolitan areas who reported being involved in more activities. 


\section{Chapter 5}

\section{Discussion}

The goals of this study were to determine if AI/AN adolescents living in Arizona perceived that adult-led in-school extracurricular activities were available to them as well as to determine their frequency of involvement and to determine if these activity variables were associated with engagement with substance use and risky behaviors. There were two hypotheses in the study which were tested by three sets of eight regressions.

\section{Hypothesis 1}

In the first hypothesis, it was predicted that the availability of adult-led in-school extracurricular activities would be related to lower substance usage and less engagement in risky substance abuse behaviors. Gender, reservation versus non-reservation status, and metropolitan versus non-metropolitan status were also examined in this hypothesis. Some of the findings supported this hypothesis. There was a significant main effect showing that when students reported that adult-led in-school extracurricular activities were available to them they were less likely to use over the counter drugs recreationally. In addition to this main effect, there were some significant interactions. There were three significant interactions between activity availability and gender and four significant interactions between activity availability and metropolitan versus non-metropolitan status.

In the results the figures show that for marijuana, prescription drugs, and reports of selling drugs that activity availability does not make a difference for females, but does make a difference for males. Therefore, the first hypothesis receives support but relative to males. Specifically, males who perceived greater activity availability reported less frequent instances of using marijuana, prescription drugs, and reports of selling drugs. Perhaps due to stereotypes of 
masculinity male students reported more instances of drug use and abuse and risky substance use behaviors. Perhaps the perception that alternative extracurricular activities are not available to males is associated with the chances that they will be more likely to participate in deviant behaviors to fill their free time. Perchance when males perceive activities as being available, they are more likely to participate in those extracurricular activities as opposed to participating in deviant behaviors such as drug use and risky substance abuse behaviors to socialize with their peers.

According to the $t$-test data females and males both perceive activities as available at the same level. The question then is why is that perception of activity availability associated with less protection from substance use and risky behaviors for males. Females in this population are already involved in more activities than males in both frequency of participation and total number of activities. Perhaps females are more involved because they search out opportunities to become more involved in their school. Females may also be sought out by teachers and volunteers to help organize activities or fund raisers. Females may be asked more often than males to help advertise a particular club or activity as well. Future research may benefit from exploring this gender difference and exploring how to make male adolescents more involved in adult-led in-school extracurricular activities that are available to them.

Gender was not the only moderator to yield significant results. Regarding metropolitan versus non-metropolitan status, those living in metropolitan areas who reported extracurricular activities were available to them reported less use of alcohol and marijuana and also were less likely to report being drunk or high at school or selling drugs. In contrast, for the nonmetropolitan youth, perceived availability of activities did not greatly impact substance use variables. The question remains as to why metropolitan adolescents who do not report activity 
availability are more likely to report using substances and participating in risky behaviors than non-metropolitan adolescents who also report no activity availability. It is worth mentioning again that the sample for this study exhibited an indication of being of lower socioeconomic status due to reports of $63 \%$ of the sample receiving free or reduced cost lunches. Perhaps adolescents in lower income metropolitan areas have fewer opportunities available to them due to less funding or schools' budgets being split among more students. Perhaps metropolitan schools do not advertise extracurricular activity opportunities as well as non-metropolitan schools. In other words, the opportunities are available but students are reporting these activities as unavailable as they are not aware of their existence. It is worth mentioning again that these adolescents all reported that they were American Indians or Alaskan Natives. These populations are at-risk and without the protective role of extracurricular activities they may be more susceptible to participate in substance use and risky substance use behaviors. Also, there could be more opportunity for engagement in substance use and risky substance use behaviors in metropolitan areas, increasing the risk for this population living in metropolitan areas. Extracurricular activities, therefore, could be especially protective with this at-risk population in a metropolitan environment. These findings support Hirschi's social control theory (2002) in that when "conventional" activities, such as extracurricular activities, are not available to adolescents they may fill their spare time with delinquent behaviors.

To summarize findings relative to the first hypothesis of availability of extracurricular activities, it was partially supported that the availability of adult-led in-school extracurricular activities is a protective factor, especially for males. The participants in this study all identified as American Indians or Alaskan Natives, but these results could potentially be replicated with participants identifying as other ethnicities. Also these findings suggest that adult-led in-school 
extracurricular activities are especially protective for adolescents living in metropolitan areas of the state of Arizona, but this may also be the trend in other states or possibly other countries. Having activities available and giving adolescents the opportunity to engage in supervised activities with their peers may be associated with a smaller chance that adolescents will fill their spare time with delinquent activities such as substance use and abuse or risky behaviors (Hirschi, 2002).

\section{Hypothesis 2}

In the second hypothesis, it was predicted that involvement in adult-led in-school extracurricular activities would be related to lower substance usage and less engagement in risky substance abuse behaviors. Involvement was measured in two ways through frequency of activity involvement and also the total number of activities in which adolescents were involved. Gender, reservation versus non-reservation status, and metropolitan versus non-metropolitan status were also examined as moderators in this hypothesis. There were two significant main effects and several significant interactions that provided support for hypothesis two. Relative to the variable of frequency of involvement in activities, greater involvement in activities was related to lower marijuana usage. Also, when participants were involved in a higher number of activities they were less likely to report being drunk or high at school. The significance of this hypothesis was also found in the interactions between frequency and number of activities with gender, reservation versus non-reservation status, and metropolitan versus non-metropolitan status.

Most of the support for the second hypothesis came from the analyses of frequency of activity involvement. There was one significant interaction between frequency of involvement in activities and gender. This interaction showed that when females were less frequently involved in 
activities they were more likely than males to ride with someone who was intoxicated or to drive while intoxicated. When reporting more activity involvement, female reports of riding with someone who was intoxicated or driving vehicles while intoxicated were actually lower. When males reported more frequent activity involvement they reported higher instances of riding with someone intoxicated or driving a vehicle intoxicated themselves. Perhaps this is due to male extracurricular activities necessitating more vehicle time; therefore, they need transportation to practices or games regardless of whether the driver is intoxicated.

Research has shown that adolescents reporting little activity involvement or much activity involvement had much higher substance usage than adolescents who were moderately involved in activities. Perhaps on the lower activity involvement level increased substance use is due to having more free time when only involved in a few activities. For the latter, the pressures of over-involvement and having little unstructured time for themselves may result in adolescents using substances to cope with too many obligations. Adolescents could potentially use substance use as a method of coping with a busy life style (Elder et al., 2000). Also, as discussed in Taylor and Turek (2010), another possibility is that substance use may be seen as "normative" in a sporting environment when team sports are involved.

There were four significant interactions regarding frequency of activity involvement and reservation versus non-reservation status. In regard to alcohol use and frequency of involvement in activities, reservation adolescents reported significantly less alcohol use with more frequent involvement in activities. Both reservation and non-reservation participants reported less use of alcohol with more frequent activity involvement. However, reservation adolescent reports of alcohol use were significantly lower with more activity involvement showing involvement is especially protective for reservation youth. The second of these four interactions reported that 
marijuana use among reservation and non-reservation youth was lower with more activity involvement. This interaction also showed that the effects were much more prominent for reservation adolescents as compared to non-reservation adolescents. The third of these four interactions involved reports of being drunk or high at school. Both reservation and nonreservation adolescents reported more instances of being drunk or high at school when they reported little activity involvement. These reports were higher among reservation adolescents with less activity involvement. When involved in activities both reservation and non-reservation adolescents reported little instance of being drunk or high at school. This showed that activities are especially protective for the reservation population.

The final interaction of this set shows that non-reservation adolescents who had reported riding with an intoxicated driver or driving a vehicle while intoxicated changed little due to activity involvement. However, reservation adolescents reported significantly less of this risky behavior when adolescents reported more activity involvement. In all four interactions regarding the reservation population, frequency of activity involvement has shown to be a tremendous protective factor with this at-risk population. Frequency of involvement could be such an important protective factor for reservation adolescents in regard to less funding by the government for schools on reservation land. This lack of funding may limit the type of activities that are available to adolescents along with how often they are able to participate in these activities. Stiffman et al. (2007) reported a negative correlation between the number of strengths reported by American Indian adolescents and the individual's substance use and abuse; these "strengths" including the opportunity to engage in an adult-led in-school extracurricular activity. With little engagement in adult-led activities, adolescents fill their spare time with alternative activities including substance use. As seen in the literature, adolescents who come from more 
affluent homes and have more opportunities at school tend to report exhibiting more prosocial and less deviant behaviors (Duncan et al., 2002). When the opportunity is available through school, adolescents in less advantageous homes may be able to choose less deviant activities in which to be a part. This choice supports Hirschi's (2002) social control theory of deviance for reservation adolescents. With more frequent involvement in activities these adolescents' recreational desires perhaps are being met through a supervised activity as opposed to deviant activities.

There were then four significant interactions between frequency of involvement in activities and metropolitan versus non-metropolitan status. The first interaction showed that metropolitan adolescents who reported lower frequency of activity involvement had higher use of marijuana than non-metropolitan adolescents. With higher activity involvement, metropolitan adolescents actually reported lower and less frequent use than non-metropolitan adolescents. The second interaction showed a similar pattern with metropolitan adolescents reporting more instances of being drunk or high at school with little activity involvement, but reporting much lower rates of being drunk or high at school including being less likely than non-metropolitan adolescents. The third interaction involved riding in a vehicle with an intoxicated driver or driving a vehicle intoxicated. For non-metropolitan adolescents there was little difference regardless of activity level. For metropolitan adolescents, with more activity involvement the reports of this risky behavior were lower than non-metropolitan students. The final interaction regarding the instance of selling drugs was very similar to the previous interaction. Little difference occurred for non-metropolitan adolescents, but metropolitan adolescents reported fewer instances of selling drugs when they were involved in activities more frequently than less frequently. This could support Hirschi's (2002) theory in that an adolescents' free time is more 
structured with more frequent involvement in activities and thus, they have less time to become engaged in delinquent behaviors, but it particularly pertains to metropolitan youth as shown in this study.

One main effect was found for the total number of adult-led in-school extracurricular activities; specifically, the more number of activities adolescents reported being involved in, the less likely they were to report being drunk or high at school. Only one significant interaction was found regarding total number of activities and it was that metropolitan adolescents were much less likely to engage in selling drugs when they had more total activities that they were involved in. In essence, this interaction was similar to the findings regarding frequency of activities. For non-metropolitan adolescents there was little difference between being involved in a small number or a large number of activities and reports of selling drugs. This shows that the total number of activities is an especially powerful protective factor for adolescents living in metropolitan areas.

To summarize, the second hypothesis was supported by two main effects found, one for frequency of involvement and one for total number of activities in which participants were involved. The majority of significance for this hypothesis came from the interactions found between frequency or number of activities along with gender, metropolitan versus nonmetropolitan status, and reservation versus non-reservation status. In these results, higher the frequency of an adolescent's involvement in one or more activities seemed to act as a protective factor against drug use or participation in risky behaviors. These results were found to be especially significant for AI/AN adolescent's living on reservations meaning that frequency of involvement in activities may be an especially protective asset against substance use and risky behavior activities with at-risk reservation adolescents (Fleming \& Ledogar, 2008). Yu and 
Stiffman (2007) found that reservation adolescents showed significantly more substance use and abuse symptoms than "urban" adolescents, therefore protection against substance use and risky behaviors is crucial to this population. Support was also found for the two theories used as the theoretical framework for this research as well. Hirschi's (2002) social control theory was used as the primary theoretical lens for viewing the results and this theory states that if an individual was involved in a group of some sort they would have less time and energy to devote to antisocial behaviors. The second theory used was the protective model of resilience theory (Fleming \& Ledogar, 2008), which states that at-risk individuals may experience a lesser negative outcome when they have resources available to them (i.e. adult-led in-school extracurricular activities).

The results regarding frequency of involvement in activities as opposed to total number of activities could be due to a strong commitment to only a few activities as opposed to spreading time across multiple activities. What is clear in this study is that frequency of involvement in activities was more important than being involved in more activities. While the hypothesis was supported by the data, the portion involving total number of activities adolescents were involved in had little significance in comparison to the frequency of activity involvement. Perhaps in future studies, more in depth research could be conducted to understand the difference between the importance of frequency of involvement and number of activities. Despite little significance regarding the total number of activities, significant findings regarding frequency of activity involvement more than supported the second hypothesis and both theories sufficiently. Limitations to this study are discussed next, followed by suggestions for future research in this field, and then finally general conclusions and implications of this thesis are presented. 


\section{Limitations}

Limitations to this study include that this data came from an existing data set. The researcher had no contact with the subjects; therefore, was unable to request additional information aside from what was provided by the Arizona Youth Survey (2010). The researcher was also unable to phrase questions in a manner chosen by the researcher but had to rely on questions and phrasing determined by the AYS (2010). For example, information regarding adolescents' perception of availability would be helpful in determining if activities were not actually available or if the adolescent was simply not aware of involvement opportunities or if they were not interested in any activity involvement regardless of publicity of availability. In regard to frequency of activity involvement, it would be helpful to ascertain the frequency of involvement for each activity. For example, if an adolescent is involved in the marching band, they may participate in practice every week day, performing at a football game on Friday night, and in a competition on Saturday. In this case, this adolescent's activity frequency may be reported much higher than an adolescent involved in school government who may attend one or two meetings a month. If each activity were examined individually, that may be found to be a more precise indicator of protection as opposed to over-all frequency of involvement in all activities.

The AYS (2010) survey relied on self-report items from adolescents regarding their various environments (i.e. home, school, and neighborhood). This could result in students leaving items blank, giving hasty answers or not answering each item truthfully. Individual attention spans and fatigue could have the students disinterested in the material and failing to answer all of the questions. If a researcher were to replicate this study, perhaps changes in the focus of questions could be made. The Arizona Youth Study (2010) was a part of a much larger 
study including questions from categories other than drug use/abuse and activity involvement. The researcher suggests that a more condensed and item specific questionnaire be instituted if a study regarding substance use and abuse were to be replicated to obtain more detailed answers from adolescents.

The researcher also did not compare reservation/non-reservation and metropolitan/nonmetropolitan in regard to overlapping populations. It would be interesting to look at reservation/metropolitan, reservation/non-metropolitan, non-reservation/metropolitan, and nonreservation/non-metropolitan categories to see where the greatest protection would be for activities. The researcher also did not look at individual activities but instead examined the total number of activities in which adolescents were involved. These pieces would be interesting and give greater insight into the protective mechanism of adult-led in-school extracurricular activities for specific individual activities. For example, to determine which types of activities held the greatest protective value to at-risk adolescents.

\section{Future Research}

Future research should focus on availability of adult-led in-school extracurricular activities for American Indian adolescents living on and off reservation land. Perhaps if there are activities available and adolescents are not taking the opportunity to participate, there is a problem with the school advertising these activities as available, or the type and quality of adultled in-school extracurricular activities available. Further, some activities require transportation and there may be constraints for adolescents in rural areas. As stated previously, the length and focus of the study should be addressed in future research. If researchers choose to investigate the link between drug use and abuse with involvement in adult-led in-school extracurricular activities, perhaps studies with fewer items should be used. Future research could benefit from a 
qualitative research approach where interviews may be conducted with students who are and who are not involved in activities. This would give the researcher and the participants a chance to further explore and explain the experience of American Indian adolescents' involvement in adult-led in-school extracurricular activities as well as their choice to use substances and engage in risky activities. This may aid researchers in understanding American Indian adolescents' choice to use and abuse substances. Longitudinal research has not been completed on this population to determine if involvement in adult-led in-school extracurricular activities really impacts drug use and abuse overtime for adolescents. Similar studies may be conducted with various minority and at-risk populations and may reveal similar results. Experimental research designs could examine program-specific outcomes of activities. Again, it would be interesting to look at reservation/metropolitan, reservation/non-metropolitan, non-reservation/metropolitan, and non-reservation/non-metropolitan categories to see where the greatest protection would be for activities.

\section{Conclusions and Applied Implications}

This study shows that adult-led in-school extracurricular activities can be beneficial for adolescents and could be a protective factor against substance use and abuse. This study adds weight to the argument that if an individual is involved in activities and thus their spare "recreational" time is filled by an organized activity an adolescent may not feel the need to fill their time with deviant activities and behaviors (Hirschi, 2002). Academic institutions may reconsider cutting budgets where adult-led in-school extracurricular activities are concerned as the overall well-being of their student population may benefit from these activities. When students thrive in one area, adult-led in-school extracurricular activities in this case, they may very well thrive in another, perhaps academics or in another area of their lives. 
This study attempted to fill gaps in this field of research regarding the benefits of adultled in-school extracurricular activities specifically for American Indian adolescents. Data was examined through the lens of social control theory (Hirschi, 2002) and resilience theory (Fleming \& Ledogar, 2008). Involvement in these activities may enhance the bond to society that Hirschi identifies as a potential deterrent to deviance (Hirschi, 2002). The model of resilience used is the protective model which emphasizes how a particular resource may reduce the negative effects of risk factors in an individual's life (Bernat \& Resnick, 2009). American Indian adolescents are a particularly at-risk population in regard to substance abuse; protective factors such as availability of and involvement in adult-led in-school extracurricular activities are important to consider. Implications of this study include that overall involvement in activities by American Indian adolescents is beneficial and is related to lower use of substances and lower instances of risky substance abuse activities. 


\section{References}

Arizona Youth Survey (2010a). Arizona youth survey: State report 2010. Retrieved from http://www.azcjc.gov/ACJC.Web/sac/AYSReports/2010/Arizona_2010_Report_Final_02 242011.pdf

Arizona Youth Survey (2010). AYS 2010 Parent letter and permission/denial slip. Retrieved from http://www.presidiohighschool.com/permissionslip2010.pdf

Beauvais, F., Jumper-Thurman, P., \& Burnside, M. (2007). The changing patterns of drug use among American Indian students over the past thirty years. American Indian \& Alaska Native Mental Health Research: The Journal of the National Center, 15, 15-24.

Bernat, \& Resnick (2009). Connectedness in the lives of adolescents. In R.J. DiClemente, J.S. Santelli, \& R.A. Crosby (Eds.), Adolescent health: Understanding and preventing risk behaviors (pp. 375-389). San Francisco, CA: Jossey-Bass.

Blum, L.M. \& Blum, R.W.M. (2009). Resilience in adolescence. In R.J. DiClemente, J.S. Santelli, \& R.A. Crosby (Eds.), Adolescent health: Understanding and preventing risk behaviors (pp. 51-76). San Francisco, CA: Jossey-Bass.

Brainy Zip (2012). Arizona zip codes. Retrieved from http://www.brainyzip.com/state/zip_arizona.html

Brave Heart, M.Y.H. (2003). The historical trauma response among natives and its relationship with substance abuse: A Lakota illustration. Journal of Psychoactive Drugs, 35, 7-13.

Centers for Disease Control and Prevention (2001). Tobacco, alcohol, and other drug use among high school students in Bureau of Indian Affairs funded schools, United States, 2001. Retrieved from http://www.cdc.gov/mmwr/preview/mmwrhtml/mm5244a3.htm

Cooley, V. E., Henriksen, L. W., Nelson, C. V., \& Thompson, J. C. Jr. (2001). A study to determine the effect of extracurricular participation on student alcohol and drug use in 
secondary schools. Journal of Alcohol and Drug Education, 40, 71-87.

Duncan, S. C., Duncan, T. E., Strycker, L. A., \& Chaumeton, N. R. (2002). Relations between youth antisocial and prosocial activities. Journal of Behavioral Medicine, 25, 425-438.

Eccles, J. S., \& Barber, B. L. (1999). Student council, volunteering, basketball, or marching band: What kind of extracurricular involvement matters? Journal of Adolescent Research, 14, 10-43.

Elder, C., Leaver-Dunn, D., Wang, M. Q., Nagy, S., \& Green, L. (2000). Organized group activity as a protective factor against adolescent substance use. American Journal of Health Behavior, 24, 108-113.

Evans-Campbell (2008). Historical trauma in American Indian/Native Alaska communities: A multilevel framework for exploring impacts on individuals, families, and communities. Journal of Interpersonal Violence, 23, 316-338.

Fleming, J., \& Ledogar, R. J. (2008). Resilience, an evolving concept: A review of literature relevant to aboriginal research. Pimatisiwin: A Journal of Aboriginal and Indigenous Community Health, 6, 7-23.

Gone, J. P., \& Calf Looking, P. E. (2011). American Indian culture as substance abuse treatment: Pursuing evidence for a local intervention. Journal of Psychoactive Drugs, 43, 291-296.

Goodluck, C., \& Wileto, A. A. A. (2009). Seeing the protective rainbow: How families survive and thrive in the American Indian and Alaska Native community. Retrieved from http://www.aecf.org/ /media/Pubs/Topics/Special\%20Interest\%20Areas/SW\%20border \%20and\%20American\%20Indian\%20Families/SeeingProtectiveRainbow/aec_indian_bri ef_10\%2007_V4.pdf

Hall, G.S. (1904). Adolescence: Its psychology and its relation to physiology, anthropology, 
sociology, sex, crime, religion, and education. Englewood Cliffs, NJ: Prentice-Hall.

Herring, R.D. (1994). Substance use among Native American Indian youth: A selected review of causality. Journal of Counseling \& Development, 72, 578-584.

Hirschi, T. (2002). Causes of delinquency. Piscataway, NJ: Transaction Publishers

Kretman, S.E., Zimmerman, M.A., Morrel-Samuels, S., \& Hudson, D. (2009). Adolescent violence: Risk, resilience, and prevention. In R.J. DiClemente, J.S. Santelli, \& R.A. Crosby (Eds.), Adolescent health: Understanding and preventing risk behaviors (pp. 213232). San Francisco, CA: Jossey-Bass.

Laub, J.H. (2011). Control theory: The life and work of Travis Hirschi. In F. Cullen, A. J. Myer, F. Adler, \& C. L. Jonson (Eds.), The origins of American criminology (pp 295-331). Piscataway, NJ: Transaction Publishers.

National Survey on Drug Use and Health, The NSDUH Report. (2004). Risk and protective factors for substance use among American Indian or Alaska Native youths. Retrieved from http://www.oas.samhsa.gov

Osilla, K.C., Lonczak, H.S., Mail, P.D., Larimer, M.E., \& Marlatt, G.A. (2007). Regular tobacco use among American Indian and Alaska Native adolescents: An examination of protective mechanisms. Journal of Ethnicity in Substance Abuse, 6, 143-153.

Peretti-Watel, P., Beck, F., \& Legleye, S. (2002). Beyond the u-curve: The relationship between sport and alcohol, cigarette and cannabis use in adolescents. Addiction, 97, 707-716.

Rothbaum, F., \& Trommsdorff, G. (2007). Do roots and wings complement or oppose one another? The socialization of relatedness and autonomy in cultural context. In J. E. Grusec, \& P. D. Hastings (Eds.), Handbook of socialization: Theory and research (pp. 461-489). New York, NY: The Guilford Press. 
Shilts, L. (1991). The relationship of early adolescent substance use to extracurricular activities, peer influence, and personal attitudes. Adolescence, 26, 613-617.

Silmere, H., \& Stiffman, A. R. (2006). Factors associated with successful functioning in American Indian youths. American Indian and Alaska Native Mental Health Research: The Journal of the National Center, 13, 23-47.

Stiffman, A. R., Brown, Ed., Freedenthal, S., House, L., Ostmann, E., \& Yu, M. S. (2007). American Indian youth: Personal, familial, and environmental strengths. Journal of Child and Family Studies, 16, 331-346.

Sutton, M.Q. (2008). An introduction to Native North America. Boston, MA: Pearson Education, Inc.

Taylor, M.J., \& Turek, G.M. (2010). If only she would play? The impact of sports participation on self-esteem, school adjustment, and substance use among rural and urban African American girls. Journal of Sport Behavior, 33, 315-336.

U.S. Census Bureau (2010a). 2010 Census results: United States: National population by race. Retrieved from http://2010.census.gov/2010census/data/

U.S. Census Bureau (2010b). 2010 Census results: Arizona: State population by race. Retrieved from http://2010.census.gov/2010census/data/

U.S. Census Bureau (2010c). 2010 Census Interactive Population Search: Arizona. Retrieved from http://2010.census.gov/2010census/popmap/ipmtext.php?fl=04

U.S. Census Bureau (2012). The American Indian and Alaska Native Population: 2010. Retrieved from http://www.census.gov/prod/cen2010/briefs/c2010br-10.pdf

Waller, M. A., Okamoto, S. K., Miles, B. W., \& Hurdle, D. E. (2003). Resiliency factors related to substance use/resistance: Perceptions of native adolescents of the southwest. Journal of 
Sociology and Social Welfare, 30, 79-94.

Werner, E. E. \& Smith, R. S. (1989). Vulnerable but invincible: A longitudinal study of resilient children and youth. New York, NY: McGraw Hill.

Yu, M. \& Stiffman, A. R. (2007). Culture and environment as predictors of alcohol abuse/dependence symptoms in American Indian youths. Addictive Behaviors, 32, 22532259. 


\section{APPENDIX A}

\section{ARIZONA YOUTH SURVEY}

1. Thank you for agreeing to participate in this survey. The purpose of this survey is to learn how students in our schools feel about their community, family, peers, and school. The survey also asks about health behaviors.

2. The survey is completely voluntary and anonymous. DO NOT put your name on the questionnaire.

3. This is not a test, so there are no right or wrong answers. We would like you to work quickly so you can finish.

4. All of the questions should be answered by completely filling in one of the answer spaces. If you do not find an answer that fits exactly, use the one that comes closest. If any question does not apply to you, or you are not sure what it means, just leave it blank. You can skip any question that you do not wish to answer.

5. For questions that have the following answers: NO! no yes YES!

Mark (the BIG) NO! if you think the statement is DEFINITELY NOT TRUE for you.

Mark (the little) no if you think the statement is MOSTLY NOT TRUE for you.

Mark (the little) yes if you think the statement is MOSTLY TRUE for you.

Mark (the BIG) YES! if you think the statement is DEFINITELY TRUE for you.

6. Please mark only one answer for each question by completely filling in the circle with a \#2 pencil.

Please fill in the following information with the help of your teacher/survey assistant.

County: Type: District: District Site:

\section{DEMOGRAPHICAL QUESTIONS:}

1.) Are you: $\bigcirc$ MALE $\circ$ FEMALE

2.) How old are you?

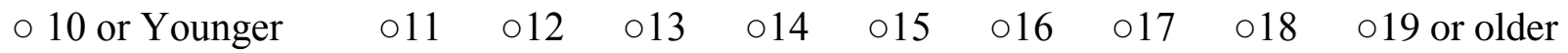


3.) What grade are you in?
$\circ 6$ th
$\circ 7$ th
○ 8th
$\circ 9$ th
○ 10th
$\circ 11$ th
$\circ 12$ th

4.) What is your race? (Mark all that apply.)

oAmerican Indian or Alaska Native

oAsian

oBlack or African American

oHawaiian or Other Pacific Islander

oWhite

5.) Are you Hispanic or Latino?

०YES $\quad$ NO

24.) Do you get a free or reduced cost lunch at school?

$\circ$ Free Lunch $\quad \circ$ Reduced Cost Lunch $\quad \circ$ Neither

\section{ACTIVITY QUESTIONS}

11.) There are lots of chances for students in my school to get involved in sports, clubs, and other school activities outside of class.

$$
\circ \mathrm{NO} ! \quad \text { ono oyes oYES! }
$$

30.) How many times in the past year (12 months) have you:

e.) participated in clubs, organizations or activities at school?
o Never
○ 1 to 2 Times
○ 3 to 5 Times
○ 6 to 9 Times
o 10 to 19 Times
○ 20 to 29 Times
- 30 to 39 Times
o 40+ Times

108.) Which school-sponsored activities are you involved in during after school hours? (Mark all that apply.)
$\circ$ Sports
○ Music
o Drama
- Foreign Language Club
oStudent Council/Government
o Newspaper/Yearbook
$\circ$ Mentoring or Tutoring
- Other school group or club
○ I am not involved in any school-sponsored activities 


\section{RISKY SUBSTANCE ABUSE ACTIVITY QUESTIONS}

30.) How many times in the past year (12 months) have you:

c.) sold illegal drugs?

$\begin{array}{llll}\circ \text { Never } & \circ 1 \text { to } 2 \text { Times } & \circ 3 \text { to } 5 \text { Times } & \circ 6 \text { to } 9 \text { Times } \\ \circ 10 \text { to } 19 \text { Times } & \circ 20 \text { to } 29 \text { Times } & \circ 30 \text { to } 39 \text { Times } & \circ 40+\text { Times }\end{array}$

i.) been drunk or high at school?
○ Never
$\circ 1$ to 2 Times
○ 3 to 5 Times
$\circ 6$ to 9 Times
- 10 to 19 Times
o 20 to 29 Times
○ 30 to 39 Times
○ 40+ Times

34.) During the past 30 days, how many times did you RIDE in a car or other vehicle driven by someone who had been drinking alcohol?

$\circ 0$ times $\quad \circ 1$ time $\quad \circ 2$ or 3 times $\quad \circ 4$ or 5 times $\quad \circ 6$ or more times

35.) During the past 30 days, how many times did you DRIVE a car or other vehicle when you had been drinking alcohol?

$\circ 0$ times $\quad \circ 1$ time $\quad \circ 2$ or 3 times $\quad \circ 4$ or 5 times $\quad \circ 6$ or more times

\section{SUBSTANCE USE QUESTIONS}

On how many occasions (if any) have you:

50.) had beer, wine or hard liquor to drink during the past 30 days?
$\circ 0 \quad \circ 1-2$
○ -5
$\circ 6-9$
$\circ 10-19$
○ 20-39
$\circ 40+$

52.) used marijuana during the past $\mathbf{3 0}$ days?
$\circ 0 \quad \circ 1-2$
○ -5
$\circ 6-9$
○10-19
○ 20-39
$\circ 40+$

54.) used LSD or other hallucinogens during the past 30 days?
$\circ 0 \quad \circ 1-2$
○-5
$\circ 6-9$
○10-19
○ 20-39
○ $40+$

56.) used cocaine or crack during the past 30 days?
$\circ 0$
$\circ 1-2$
○3-5
०6-9
o10-19
○ 20-39
○ $40+$ 
58.) sniffed glue, breathed the contents of an aerosol spray can, or inhaled other gases or sprays, in order to get high during the past 30 days?

$\circ 0 \quad 01-2 \quad 03-5 \quad 06-9 \quad 010-19 \quad 020-39 \quad \circ 40+$

60.) used phenoxydine in the past 30 days?

$\circ 0 \quad \circ 1-2 \quad 03-5 \quad 06-9 \quad 010-19 \quad 020-39 \quad \circ 40+$

62.) used methamphetamines (meth, crystal meth) in the past 30 days?

$\circ 0 \quad \circ 1-2 \quad \circ 3-5 \quad 06-9 \quad \circ 10-19 \quad \circ 20-39 \quad \circ 40+$

64.) used heroin/opiates in the past 30 days?
$\circ 0 \quad \circ 1-2$
o3-5
०6-9
○10-19
○ 20-39
$\circ 40+$

66.) used ecstasy in the past 30 days?
$\circ 0$
$\circ 1-2$
○ $3-5$
$\circ 6-9$
○10-19
○ 20-39
$\circ 40+$

68.) used steroids or anabolic steroids in the past 30 days?
$\circ 0$
$\circ 1-2$
○3-5
$\circ 6-9$
○10-19
○ 20-39
○ $40+$

70.) used prescription pain relievers (such as Vicodin, Oxycontin, Percocet, or Codeine) without a doctor telling you to take them during the past 30 days?
$\circ 0$
० 1-2
०3-5
०6-9
o10-19
○ 20-39
○ 40+

72.) used prescription stimulants in the past $\mathbf{3 0}$ days?
$\circ 0$
०1-2
○3-5
०6-9
○10-19
ค 20-39
○ $40+$

74.) used prescription sedatives in the past $\mathbf{3 0}$ days?
$\circ 0$
०1-2
o3-5
०6-9
○10-19
ค 20-39
○ 40+

76.) used over the counter drugs (such as cough syrup, cold medicine, or diet pills) for the purposes of getting high during the past 30 days?
$\circ 0 \quad \circ 1-2$
०3-5
o6-9
○10-19
○ 20-39
○ 40+ 


\section{Appendix B}

\section{Example Parent Informational Letter}

Dear Parents or Guardian:

Our school is participating in the Arizona Youth Survey, a statewide needs assessment study sponsored by the Arizona Criminal Justice Commission. Presidio School will be administering this survey on Tuesday, May 4, 2010, to the school's 8th (Eagles), 10th, and 12th grade students. The study results will be used to assess current prevention programs as well as help plan future substance abuse prevention programs in our community. Some important facts about the survey:

1. It is anonymous. Students will be instructed to not put their names on the survey questionnaire. No one will be able to connect any individual student with his or her responses. School staff will not see any students' responses.

2. Participation in the survey is voluntary. Your son/daughter may decline to participate at any time or skip any question he/she does not wish to answer.

Questions cover alcohol, drugs, tobacco, and family and community factors related to substance abuse.

I hope that you will agree to allow your child to participate in this statewide effort that will help create better, more effective programming to combat the problem of alcohol and drug use by youth in our community. If you agree, you do not need to do anything. However, if you do not wish your child to participate, please complete and return the attached denial of permission slip to Joy Barr by April 23, 2010 and your child will be excused from participation.

The materials used in the survey are available for your inspection at the front reception area and on the school's website: www.presidiohighschool.com. If you have any questions regarding the survey or your child's participation, please contact Joy Barr.

Thank you in advance for your cooperation.

Sincerely,

Terry Garza

Co-Director

\section{DO NOT give permission for my child to participate in the Arizona Youth Survey. Please print clearly.}

Child's Name:

Parent's Name:

Parent's Signature:

Date of Signature: 


\section{Appendix C}

\section{Data Sharing Agreement}

\section{INTERAGENCY AGREEMENT BETWEEN \\ AUG 062012 THE ARIZONA CRIMINAL JUSTICE COMMMISSION, AND}

(Agency Name, hereinafter User)

The Arizona Criminal Justice Commission (hereinafter ACJC), and the User, hereby agree to the following terms, provisions, and conditions:

\section{Purpose:}

(1) User has a need for Arizona Youth Survey (AYS) data for research purposes. The ACJC, in its capacity as agency responsible for administration of the AYS, has the authorization to provide these data pursuant to the applicable Arizona Revised Statutes. This Agreement establishes the terms of this relationship.

\section{Effective Date and Duration:}

(1) This agreement will take effect upon execution of the signatures of the Director of the ACJC and the User. This agreement will continue for thirty (30) days past the research project completion date as designated in an approved Institutional Review Board Application. Any party may cancel this agreement upon thirty (30) days written notice to the other parties. This agreement may be extended by written agreement of all parties and the ACJC approval of Institutional Review Board Documentation regarding the extension.

\section{Services ACJC agrees to provide:}

(1) A research project specific AYS dataset including only information authorized by law to be released.

\section{Duties of User:}

User agrees to undertake and perform the following duties:

(1) User agrees to maintain AYS data and all documents related to this Agreement, including Institutional Review Board documentation and approval, correspondence, this signed Agreement and all applicable Arizona Administrative Code and Code of Federal Regulations provisions in order to facilitate audits. User shall make these records available to the ACJC for the purpose of conducting such audits to ensure compliance with all laws, rules, and regulations regarding the processing of AYS data furnished ACJC to User. At a minimum, User shall $\log$ all AYS data received from the ACJC. Such log shall be retained by User for a period of (3) years after the project's completion date.

(2) User shall be responsible for the physical security of AYS data under its control or in its custody and shall protect such information from unauthorized access, disclosure, or dissemination. When AYS data is no longer required by User, data 
shall be destroyed by User through shredding or burning of paper documentation and any digital media such as CD ROM and deletion of electronic AYS data from User's databases, computers, and networks. User shall notify ACJC of intended AYS data destruction in writing thirty (30) days prior to the act. User shall destroy all AYS data through shredding, burning, and deletion not later than thirty (30) days after the completion date of the project. After such destruction, User shall certify in writing to the ACJC that such destruction has been accomplished, the nature of all media destroyed, and the means by which such destruction has been accomplished within thirty (30) days after destruction.

(3) User shall not further disseminate AYS data to any entity or individual except upon written permission from the ACJC. Any such entity to which or individual to whom such permission may be granted shall agree in writing to abide by all the terms of this Agreement.

(4) User shall comply with all the provisions of Government Anti-Identification Procedures (ARS 41-4172).

(5) To the extent permitted by Arizona law, User agrees to assume all risk of harm and to indemnify and hold harmless, the State of Arizona, the ACJC, their officers, agents and employees, from any and all liabilities, demands, claims, suits, losses, damages, including judgments, fines and attorneys' fees, which may be incurred as a result of the User's possession and use of AYS data, except to the extent caused by the negligence or willful misconduct of any of the indemnified parties.

\section{Duties of The ACJC:}

The ACJC agree to undertake and perform the following duties:

(1) The ACJC shall process, in a timely fashion, according to the nature of the request, all requests for AYS data submitted by User.

(2) The ACJC shall provide User with an AYS dataset that includes the specific data elements described in their request for AYS data.

(3) The ACJC may, if requested, assist User in the interpretation or translation of any AYS data requiring clarification.

\section{General Provisions:}

(1) The ACJC agree to notify User sixty (60) days prior to making changes in rules, procedures, and policies adopted by it and incorporated in this agreement.

Changes in the rules, procedures, and policies originating with federal and state executive order, congressional or state legislative enactment, or by court decision shall be initiated as required by law. 


\section{Appendix A: Arizona Criminal Justice Commission Confidentiality Agreement}

This agreement is between the Arizona Criminal Justice Commission (hereinafter the "Commission") and Carol Markstrom, Ph.D and Lizzy Jones (hereinafter "User") regarding the confidentiality of Arizona Youth Survey data collected by the Arizona Criminal Justice Commission and for research purposes. The data covered by this agreement are Arizona Youth Survey data that pertains to the attitudes and behaviors of $8^{\text {th }}, 10^{\text {th }}$, and $12^{\text {th }}$ grade youth and the circumstances in which they live. The paragraphs listed below dictate the use of such data and the dissemination of information that is developed from this data. In consideration of the furnishing of Arizona Youth Survey data, the User and Commission agree as follows:

1. Access to Arizona Youth Survey data is being given to the User for the express purpose of supporting a study entitled The Protective Benefits of Adult-Led InSchool Extracurricular Activities on American Indian Adolescents Drug Use.

2. Prior to being granted access to the information, the User will furnish the Commission with the full name and title of each person that will access the data. The User will furnish the Commission with similar information as to any person who may subsequently seek to access the data. No person shall be permitted to access the data until the Commission shall grant access and the Commission will notify the User when such access has been granted.

3. All materials produced by the User will contain sufficient protections to ensure the confidentiality and anonymity of participating schools and school districts. No data or analyses will be disseminated that will describe or identify an individual record subject. No names, street addresses or other information that could reasonably be used to identify a school, school district, or respondent will be disseminated.

4. The data and/or records will be used exclusively for research purposes. All research materials produced from the data, including draft publications, shall be shared at no cost with the Commission prior to any dissemination for the purpose of reviewing the information developed from the data to ensure compliance with this agreement and the protection of record subject confidentiality.

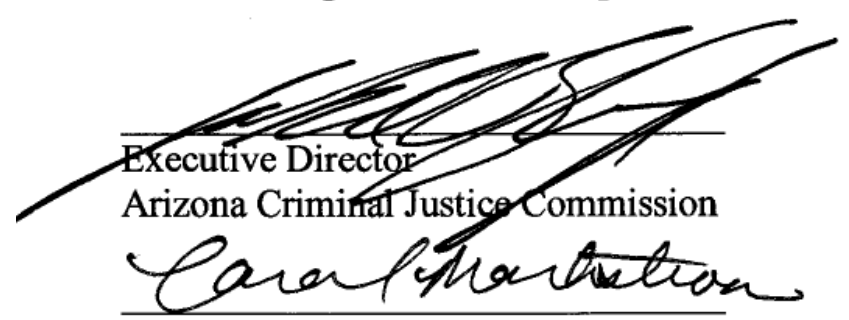

Carol Markstrom, Ph.D., Advisor

$$
\text { hustin } 2 \text { Molanew }
$$

Kristin Moilanen, Ph.D., Committee Member

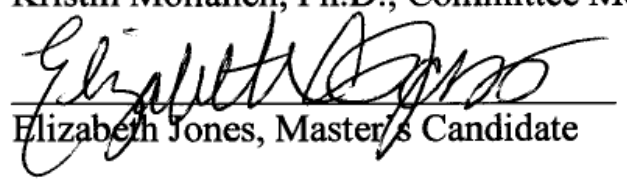

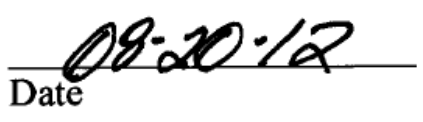

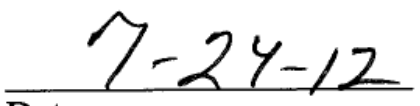

Date

$$
7-24-2012
$$

Date

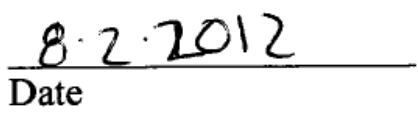



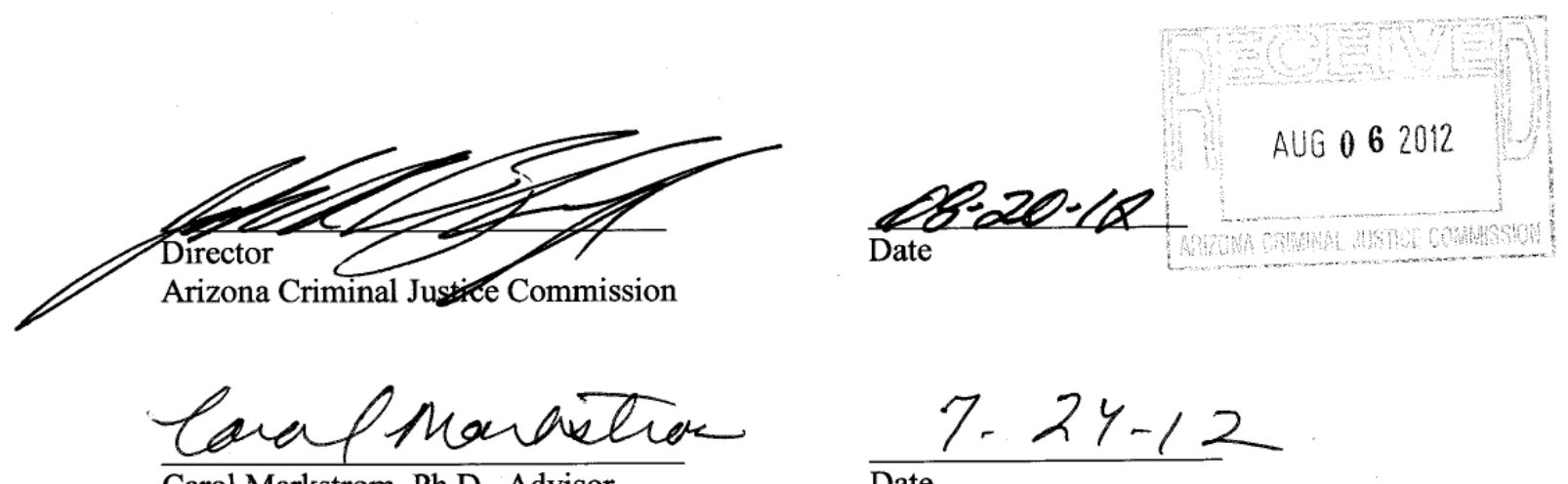

Carol Markstrom, Ph.D., Advisor

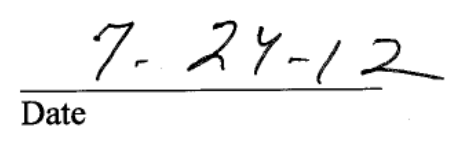

Kustic 2 Mnlanew Kristin Moilanen, Ph.D., Committee Member

$\frac{7-24-2012}{\text { Date }}$
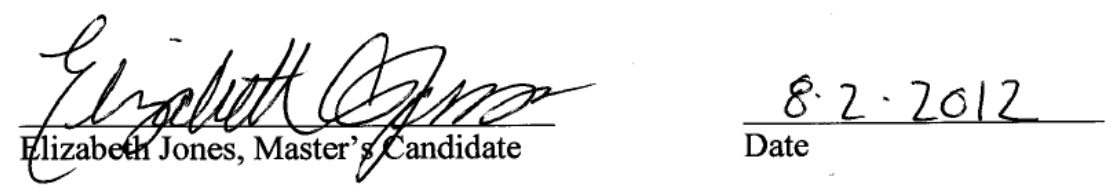

Attachments:

Appendix A Arizona Criminal Justice Commission Confidentiality Agreement 


\section{Tables}

Table 1:

Demographics for Sample

\begin{tabular}{llcc}
\hline Variable & Value & Number & Percentage \\
\hline Gender & Female & 2757 & $49.1 \%$ \\
& Male & 2858 & $50.9 \%$ \\
\hline Grade & $8^{\text {th }}$ Grade & 2634 & $46.2 \%$ \\
& $10^{\text {th }}$ Grade & 1812 & $31.8 \%$ \\
& $12^{\text {th }}$ Grade & 1255 & $22 \%$ \\
\hline SES & Free or Reduced Cost Lunch & 3488 & $62.7 \%$ \\
& No Cost Reduction Lunch & 2075 & $37.3 \%$ \\
\hline Race & Solely AI/AN & 3724 & $68.0 \%$ \\
& AI/AN and 1 or more ethnicity & 1821 & $31.9 \%$ \\
& AI/AN and Hispanic & 1816 & $33.2 \% *$ \\
\hline Metropolitan Status & Metropolitan & 2574 & $45.9 \%$ \\
& Non-Metropolitan & 3036 & $54.1 \%$ \\
\hline Reservation Status & Reservation & 1650 & $28.9 \%$ \\
& Non-Reservation & 4051 & $71.1 \%$ \\
\hline
\end{tabular}

* This number and frequency was based on the total of 5,475 who answered the question on Hispanic origin. 
Table 2

Table of Variables

\begin{tabular}{|c|c|}
\hline \multicolumn{2}{|c|}{ Dependent Variables } \\
\hline Variable & Survey Item Number \\
\hline Alcohol Use & 50.) Alcohol \\
\hline Marijuana Use & 52.) Marijuana \\
\hline \multirow{8}{*}{ Illicit Drug Use } & 54.) LSD/Hallucinogens \\
\hline & 56.) Cocaine/Crack \\
\hline & 58.) Inhalants \\
\hline & 60.) Phenoxydine \\
\hline & 62.) Methamphetamines \\
\hline & 64.) Heroin/Opiates \\
\hline & 66.) Ecstasy \\
\hline & 68.) Steroids or Anabolic Steroids \\
\hline \multirow[t]{3}{*}{ Pharmaceutical Drug Use } & 70.) Prescription Pain Relievers \\
\hline & 72.) Prescription Stimulants \\
\hline & 74.) Prescription Sedatives \\
\hline Over the Counter Drug Use & 76.) Over the Counter Drugs \\
\hline Drunk/High at School & 30i.) Been Drunk or High at School \\
\hline \multirow[t]{2}{*}{ Ride/Drive } & $\begin{array}{l}\text { 34.) Ridden in a car with a driver who had } \\
\text { been drinking alcohol. }\end{array}$ \\
\hline & 35.) Driven a car after drinking alcohol. \\
\hline \multirow[t]{2}{*}{ Selling Drugs } & 30c.) Sold Illegal Drugs \\
\hline & Independent Variables \\
\hline Variable & Survey Item Number \\
\hline Availability & $\begin{array}{l}\text { 11.) There are lots of chances for students in } \\
\text { my school to get involved in sports, clubs, and } \\
\text { other school activities outside of class. }\end{array}$ \\
\hline Frequency & $\begin{array}{l}\text { 30e.) How many times in the past year ( } 12 \\
\text { months) have you participated in clubs, } \\
\text { organizations or activities at school? }\end{array}$ \\
\hline \multirow[t]{3}{*}{ Number } & $\begin{array}{l}\text { 108.) Which school-sponsored activities are } \\
\text { you involved in during after school hours? }\end{array}$ \\
\hline & g Variables \\
\hline & Survey Item Number \\
\hline Gender & 1.) Are you: Male or Female \\
\hline Metropolitan versus Non-Metropolitan & Student's Zip Code \\
\hline Reservation versus Non-Reservation & Student's Zip Code \\
\hline
\end{tabular}


Table 3

Summary of Bivariate Correlations Between Dependent and Independent Variables

\begin{tabular}{|c|c|c|c|c|c|c|c|c|c|c|c|}
\hline Variable & 1 & 2 & 3 & 4 & 5 & 6 & 7 & 8 & 9 & 10 & 11 \\
\hline 1. Alcohol & - & & & & & & & & & & \\
\hline 2. Marijuana & $.49 * *$ & - & & & & & & & & & \\
\hline 3. Illicit Drugs & $.34 * *$ & $.34 * *$ & - & & & & & & & & \\
\hline 4. Prescription Drugs & .30 & .23 & .32 & - & & & & & & & \\
\hline 5. Over The Counter Drugs & .21 & .16 & .24 & $.39 * *$ & - & & & & & & \\
\hline 6. Ride/Drive & $.51 * *$ & $.36 * *$ & .27 & .23 & .21 & - & & & & & \\
\hline 7. Drunk/High & $.50 * *$ & $.65^{* *}$ & $.33 * *$ & .26 & .19 & $.41 * *$ & - & & & & \\
\hline 8. Selling Drugs & $.40 * *$ & $.45^{* *}$ & .31 & .24 & .15 & $.35 * *$ & $.51 * *$ & - & & & \\
\hline 9. Activity Availability & -.09 & -.10 & -.07 & -.08 & -.06 & -.10 & -.09 & -.08 & - & & \\
\hline 10. Activity Frequency & -.05 & -.11 & -.05 & -.02 & -.01 & -.06 & -.08 & -.04 & .18 & - & \\
\hline 11. Activity Number & -.03 & -.09 & -.01 & -.03 & -.00 & -.03 & -.08 & -.05 & .12 & $.44 * *$ & - \\
\hline
\end{tabular}

** $p$ value is significant $(<.05)$ at the $(+$ or -$) 0.33$ level 
Table 4

\section{T-test Information Regarding Gender}

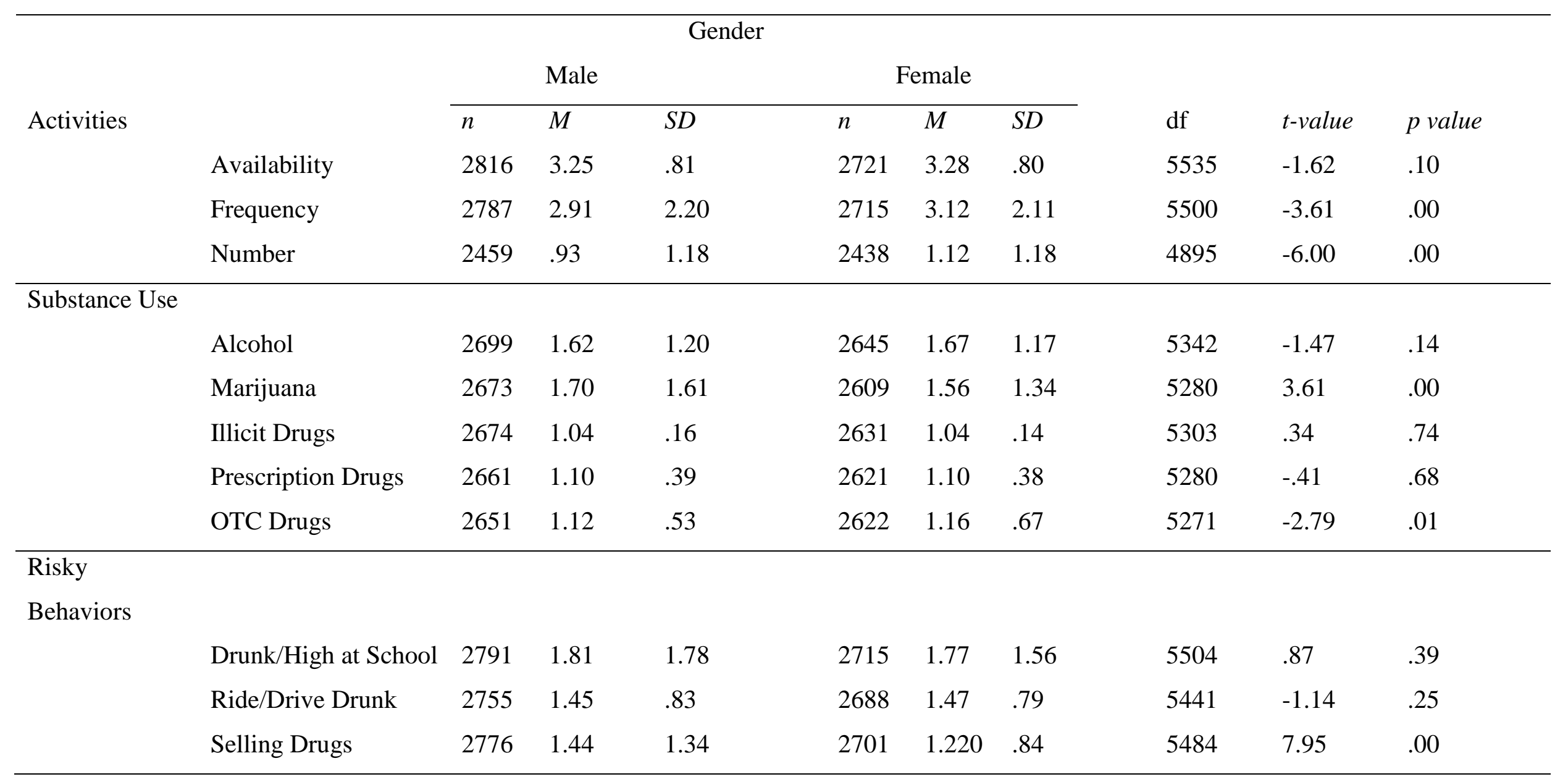


Table 5

t-test Information Regarding Metropolitan Versus Non-Metropolitan Status

\begin{tabular}{|c|c|c|c|c|c|c|c|c|c|c|}
\hline \multicolumn{11}{|c|}{ Metropolitan Versus Non-Metropolitan Status } \\
\hline & & \multicolumn{3}{|c|}{ Metropolitan } & \multicolumn{3}{|c|}{ Non-Metropolitan } & \multirow[b]{2}{*}{ df } & \multirow[b]{2}{*}{ t-value } & \multirow[b]{2}{*}{$p$ value } \\
\hline Activities & & $n$ & $M$ & $S D$ & $n$ & $M$ & $S D$ & & & \\
\hline & Availability & 2543 & 3.25 & .82 & 2989 & 3.29 & .78 & 5530 & 1.62 & .11 \\
\hline & Frequency & 2528 & 3.05 & 2.24 & 2967 & 2.98 & 2.09 & 5493 & -1.06 & .29 \\
\hline & Number & 2219 & .99 & 1.12 & 2669 & 1.05 & 1.11 & 4886 & 1.81 & .07 \\
\hline \multicolumn{11}{|c|}{ Substance Use } \\
\hline & Alcohol & 2448 & 1.68 & 1.25 & 2885 & 1.62 & 1.14 & 5331 & -1.84 & .07 \\
\hline & Marijuana & 2414 & 1.59 & 1.48 & 2856 & 1.66 & 1.50 & 5268 & 1.72 & .09 \\
\hline & Illicit Drugs & 2424 & 1.04 & .16 & 2868 & 1.03 & .16 & 5290 & -1.58 & .11 \\
\hline & Prescription Drugs & 2413 & 1.11 & .41 & 2856 & 1.10 & .36 & 5267 & -1.11 & .27 \\
\hline & OTC Drugs & 2409 & 1.15 & .62 & 2852 & 1.13 & .58 & 5259 & -1.01 & .31 \\
\hline \multicolumn{11}{|c|}{ Risky Behaviors } \\
\hline & Drunk/High at School & 2531 & 1.73 & 1.66 & 2969 & 1.84 & 1.69 & 5498 & 2.46 & .01 \\
\hline & Ride/Drive Drunk & 2492 & 1.45 & .81 & 2942 & 1.46 & .81 & 5432 & .82 & .41 \\
\hline & Selling Drugs & 2524 & 1.33 & 1.18 & 2957 & 1.31 & 1.11 & 5479 & -.52 & .60 \\
\hline
\end{tabular}


Table 6

t-test Information Regarding Reservation Versus Non-Reservation Status

\begin{tabular}{|c|c|c|c|c|c|c|c|c|c|c|}
\hline & \multicolumn{10}{|c|}{ Reservation Versus Non-Reservation Status } \\
\hline & & \multicolumn{3}{|c|}{ Reservation } & \multicolumn{3}{|c|}{ Non-Reservation } & & & \\
\hline \multirow[t]{4}{*}{ Activities } & & $n$ & $M$ & $S D$ & $n$ & $M$ & $S D$ & df & t-value & $p$ value \\
\hline & Availability & 1630 & 3.22 & .80 & 3992 & 3.28 & .80 & 5620 & 2.40 & .02 \\
\hline & Frequency & 1615 & 2.90 & 2.01 & 3970 & 3.05 & 2.21 & 5583 & 2.37 & .02 \\
\hline & Number & 1427 & 1.04 & 1.11 & 3545 & 1.01 & 1.12 & 4970 & -.848 & .40 \\
\hline \multicolumn{11}{|c|}{ Substance Use } \\
\hline & Alcohol & 1570 & 1.63 & 1.13 & 3854 & 1.66 & 1.21 & 5422 & .91 & .36 \\
\hline & Marijuana & 1550 & 1.78 & 1.58 & 3809 & 1.57 & 1.44 & 5357 & -4.69 & .00 \\
\hline & Illicit Drugs & 1555 & 1.03 & .16 & 3827 & 1.04 & .15 & 5380 & 1.10 & .27 \\
\hline & Prescription Drugs & 1550 & 1.09 & .34 & 3809 & 1.11 & .41 & 5357 & 2.19 & .03 \\
\hline & OTC Drugs & 15550 & 1.11 & .53 & 3801 & 1.15 & .63 & 5349 & 2.06 & .04 \\
\hline \multicolumn{11}{|c|}{ Risky Behaviors } \\
\hline & Drunk/High at School & 1618 & 2.00 & 1.78 & 3972 & 1.70 & 1.63 & 5588 & -6.08 & .00 \\
\hline & Ride/Drive Drunk & 1600 & 1.51 & .85 & 3925 & 1.44 & .80 & 5523 & -3.17 & .00 \\
\hline & Selling Drugs & 1609 & 1.36 & 1.20 & 3961 & 1.30 & 1.11 & 5568 & -1.67 & .09 \\
\hline
\end{tabular}


Table 7

Summary of Regression Models Predicting Substance Use From Availability of In-School Extracurricular Activities

Model

\begin{tabular}{|c|c|c|c|c|c|c|c|c|}
\hline Variable & Alcohol & Marijuana & $\begin{array}{l}\text { Illicit } \\
\text { Drugs }\end{array}$ & Rx Drugs & $\begin{array}{l}\text { OTC } \\
\text { Drugs }\end{array}$ & $\begin{array}{l}\text { Drunk/ } \\
\text { High at } \\
\text { School }\end{array}$ & Ride/Drive & $\begin{array}{l}\text { Selling } \\
\text { Drugs }\end{array}$ \\
\hline Sex & -.02 & $.05 * * *$ & .01 & -.01 & $-.04 * *$ & .01 & -.01 & $.11 * * *$ \\
\hline Grade in School & $.16^{* * *}$ & $.16^{* * *}$ & -.01 & $.05^{* *}$ & .01 & $.13 * * *$ & .02 & $.09 * * *$ \\
\hline Metro & .02 & .01 & .02 & -.01 & -.01 & .01 & .01 & .02 \\
\hline Extracurricular Activity & -.03 & -.03 & -.03 & -.03 & $-.07 *$ & -.04 & -.05 & .00 \\
\hline \multicolumn{9}{|l|}{ Availability } \\
\hline Availability x Sex & .00 & $-.04 *$ & -.02 & $-.05 *$ & .01 & -.02 & -.02 & $-.06 * *$ \\
\hline$R^{2}$ & $.03^{*}$ & $.04^{*}$ & $.01 * *$ & $.01 * *$ & $.01 * *$ & $.03 *$ & $.01 * *$ & $.03^{*}$ \\
\hline
\end{tabular}

Note. $\mathrm{Rx}=$ Prescription, $\mathrm{OTC}=$ Over the counter, Metro= Metropolitan. All weights are standardized. $* p<.05, * * p<.01, * * * p<$ .001 . 
Table 8

Summary of Regression Models Predicting Substance Use From Frequency of Involvement In In-School Extracurricular Activities

Model

\begin{tabular}{|c|c|c|c|c|c|c|c|c|}
\hline Variable & Alcohol & Marijuana & $\begin{array}{l}\text { Illicit } \\
\text { Drugs }\end{array}$ & Rx Drugs & $\begin{array}{l}\text { OTC } \\
\text { Drugs }\end{array}$ & $\begin{array}{l}\text { Drunk/ } \\
\text { High at } \\
\text { School }\end{array}$ & Ride/Drive & $\begin{array}{l}\text { Selling } \\
\text { Drugs }\end{array}$ \\
\hline Sex & .02 & $-.05^{* * *}$ & -.00 & .00 & $.04 * *$ & -.01 & .01 & $-.11 * * *$ \\
\hline Grade in School & $.17 * * *$ & $.17 * * *$ & .00 & $.05 * * *$ & .01 & $.14 * * *$ & $.03 *$ & $.09 * * *$ \\
\hline SES & .01 & $.04 *$ & -.02 & -.02 & .02 & .02 & .02 & -.00 \\
\hline Lives on Reservation & -.02 & $.04 *$ & .00 & $-.04 *$ & $-.04 *$ & $.06 * * *$ & $.04 *$ & .02 \\
\hline Metro & .02 & .01 & .02 & -.01 & -.00 & .01 & .02 & .02 \\
\hline $\begin{array}{l}\text { Frequency of Involvement } \\
\text { in In-School Activities }\end{array}$ & -.05 & $-.07 *$ & -.01 & -.01 & -.03 & -.06 & -.04 & -.01 \\
\hline Frequency x Sex & .04 & .01 & -.01 & .02 & .03 & .03 & $.05^{*}$ & -.01 \\
\hline Frequency x Reservation & $-.04 *$ & $-.05 * *$ & -.01 & -.02 & .01 & $-.04 *$ & $-.05 *$ & -.02 \\
\hline Frequency x Metro & -.03 & $-.05^{*}$ & -.04 & -.03 & -.01 & $-.06 * *$ & $-.05 *$ & $-.04 *$ \\
\hline$R^{2}$ & $.03 *$ & $.05^{*}$ & $.00 * * *$ & $.01 * *$ & $.00 * * *$ & $.04 *$ & $.01 * *$ & $.02 *$ \\
\hline
\end{tabular}

Note. $\mathrm{Rx}=$ Prescription, $\mathrm{OTC}=$ Over the counter, Metro= Metropolitan. All weights are standardized. $* p<.05, * * p<.01, * * * p<$ .001 . 
Table 9

Summary of Regression Models Predicting Substance Use From Number Of In-School Extracurricular Activities Adolescents are Involved In.

\begin{tabular}{|c|c|c|c|c|c|c|c|c|}
\hline & & & Model & & & & & \\
\hline Variable & Alcohol & Marijuana & $\begin{array}{l}\text { Illicit } \\
\text { Drugs }\end{array}$ & Rx Drugs & $\begin{array}{l}\text { OTC } \\
\text { Drugs }\end{array}$ & $\begin{array}{l}\text { Drunk/ } \\
\text { High at } \\
\text { School }\end{array}$ & Ride/Drive & $\begin{array}{l}\text { Selling } \\
\text { Drugs }\end{array}$ \\
\hline Sex & .02 & $-.05 * *$ & -.00 & .01 & $.03^{*}$ & -.02 & .01 & $-.11 * * *$ \\
\hline Grade in School & $.15^{* * *}$ & $.15^{* * *}$ & -.00 & $.05 * *$ & .01 & $.12 * * *$ & .01 & $.08 * * *$ \\
\hline SES & .01 & $.04 *$ & -.02 & -.02 & .02 & .02 & .03 & -.01 \\
\hline Lives on Reservation & -.02 & $.05^{* *}$ & -.00 & $-.04 *$ & $-.05 * *$ & $.06 * * *$ & $.04 *$ & .03 \\
\hline Metro & .02 & .01 & .01 & -.01 & -.01 & .01 & .01 & .02 \\
\hline Number of Activities & -.01 & -.04 & .04 & -.02 & -.01 & $-.08 * *$ & -.05 & .01 \\
\hline \multicolumn{9}{|l|}{ Involved In } \\
\hline \# Activities x Sex & -.01 & -.02 & -.01 & -.01 & .02 & .01 & .03 & -.01 \\
\hline \# Activities x Reservation & -.01 & -.03 & -.01 & .01 & .00 & .01 & .00 & -.01 \\
\hline \# Activities x Metro & -.01 & -.03 & -.04 & -.02 & -.02 & -.03 & -.01 & $-.06 *$ \\
\hline$R^{2}$ & .02 & .04 & .00 & .01 & .00 & .03 & .01 & .03 \\
\hline
\end{tabular}

Note. $\mathrm{Rx}=$ Prescription, $\mathrm{OTC}=$ Over the counter, Metro= Metropolitan. All weights are standardized. $* p<.05, * * p<.01, * * * p<$ .001 . 
Figure 1

Hypothesis 1: Availability of adult-led in-school extracurricular activities will be related to lower substance usage and less engagement in risky substance abuse activities. Gender, metropolitan versus non-metropolitan status, and reservation versus non-reservation status will be examined in these hypotheses.

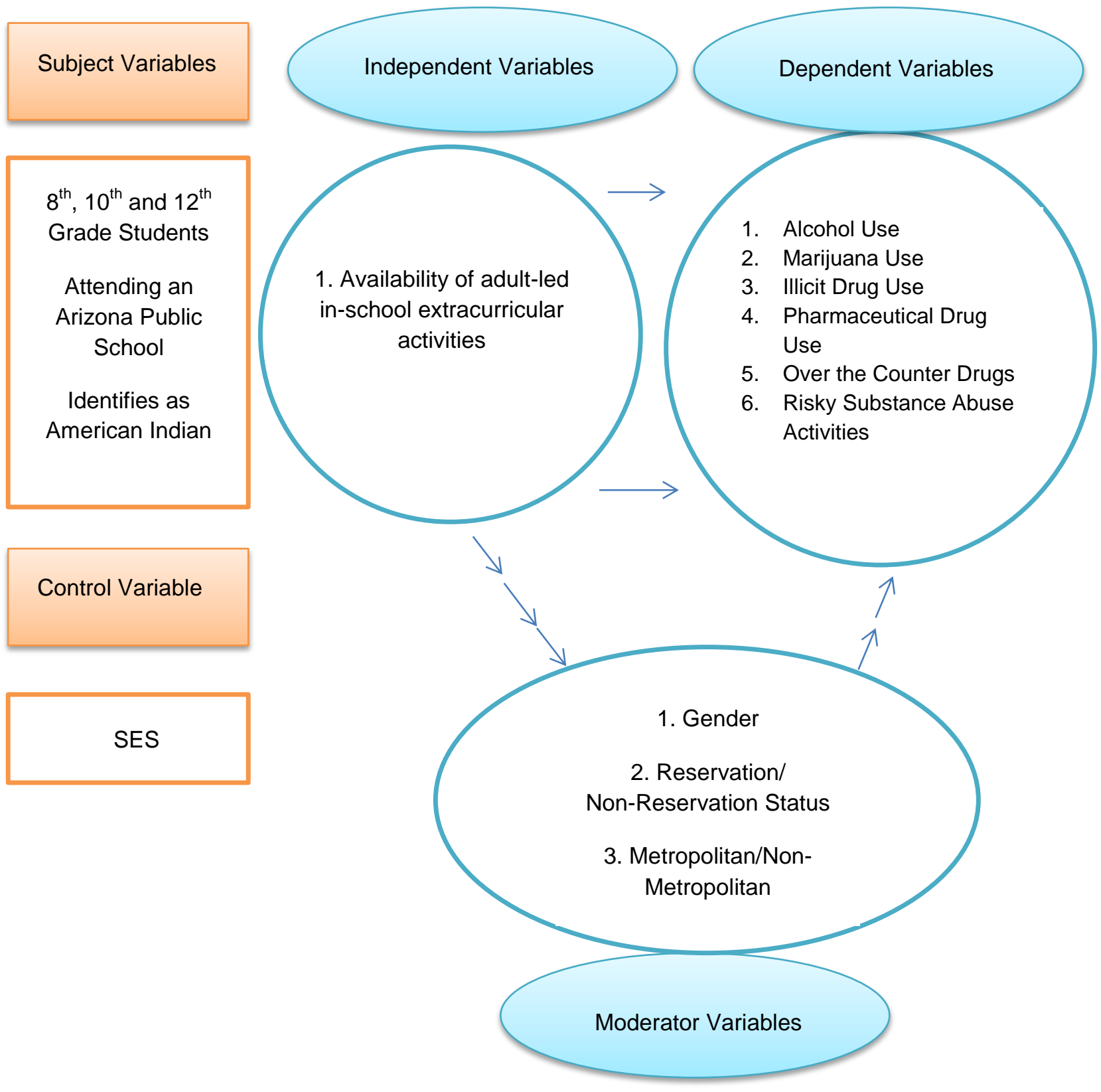


Figure 2

Hypothesis 2: Greater involvement in adult-led in-school extracurricular activities will be related to lower substance usage and less engagement in risky substance abuse activities. Gender, metropolitan versus non-metropolitan status, and reservation versus nonreservation status will be examined in these hypotheses.

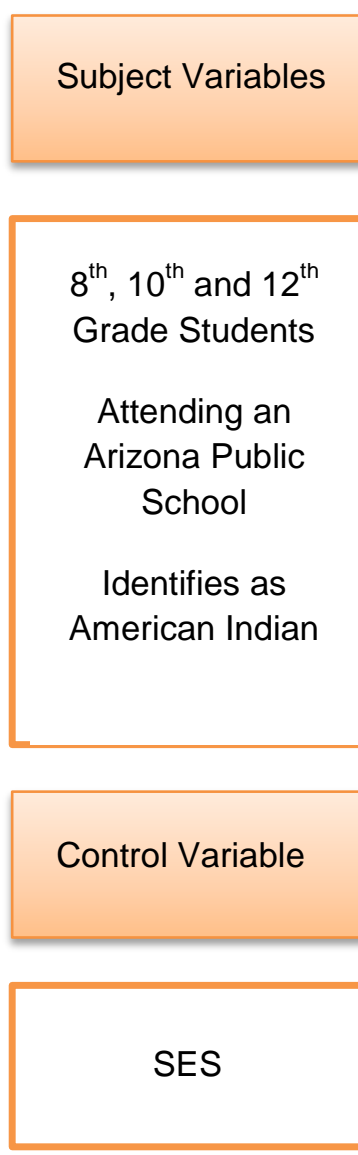

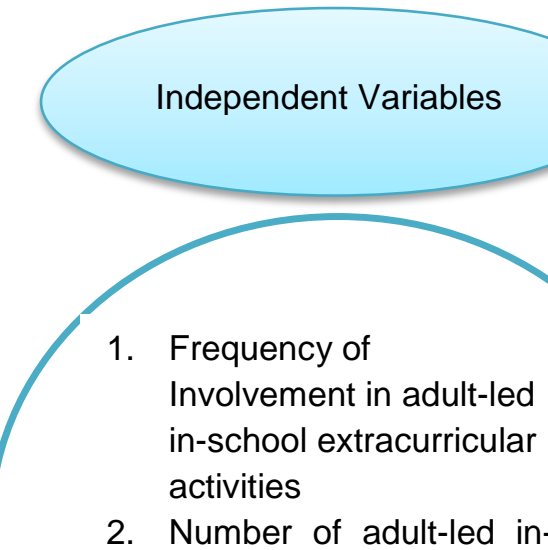

2. Number of adult-led inschool extracurricular activities involved in

\section{Dependent Variables}

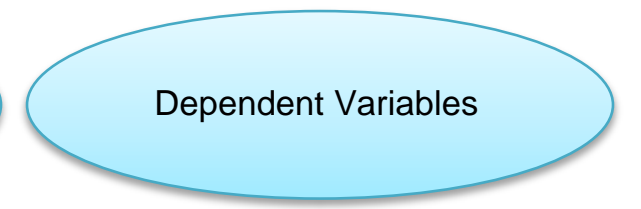

1. Alcohol Use

2. Marijuana Use

3. Illicit Drug Use

4. Pharmaceutical Drug Use

5. Over the Counter Drugs

6. Risky Substance Abuse Activity

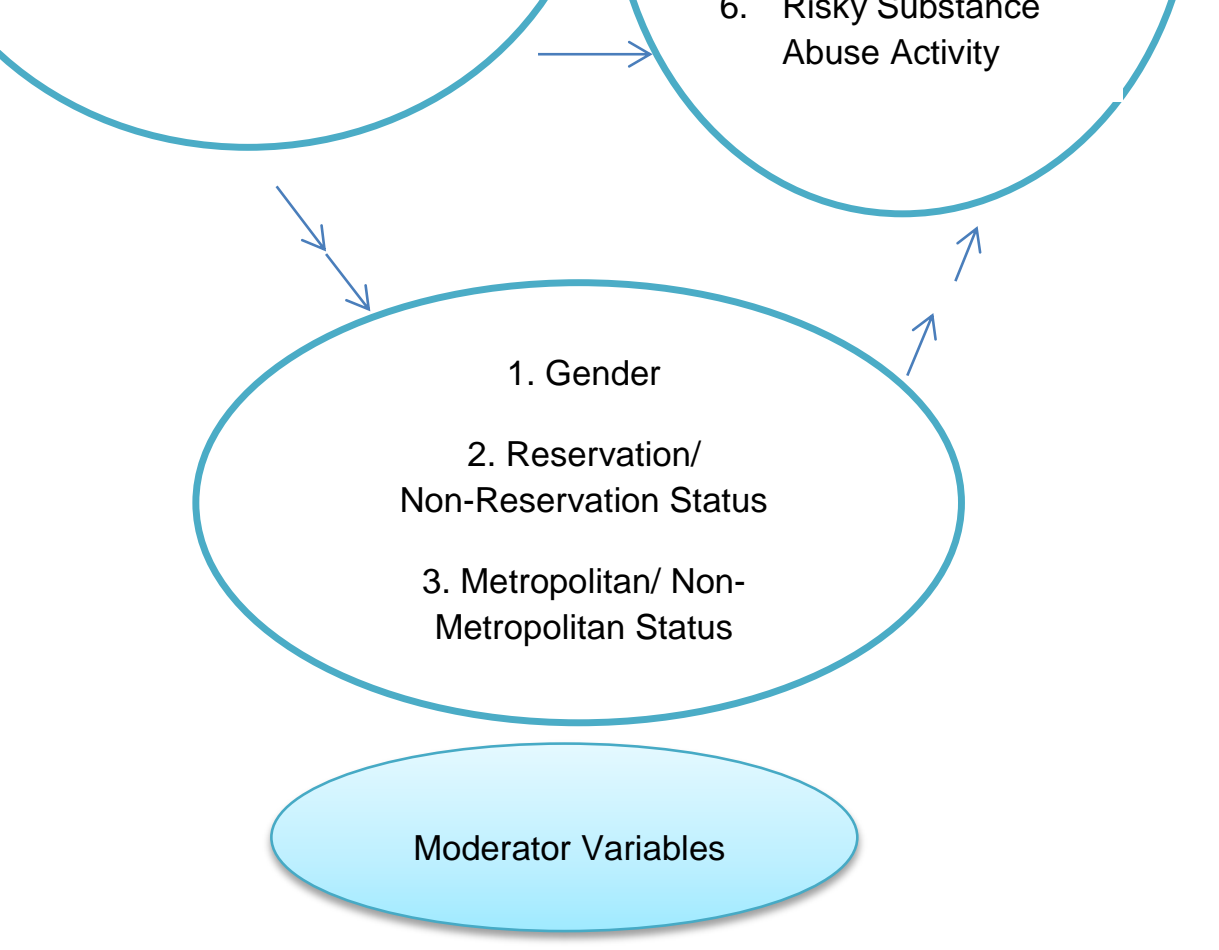


Figure 3

Interaction of Availability of Adult-Led In-School Extracurricular Activities, Metropolitan Status, and Reported Alcohol Use in the Past 30 Days

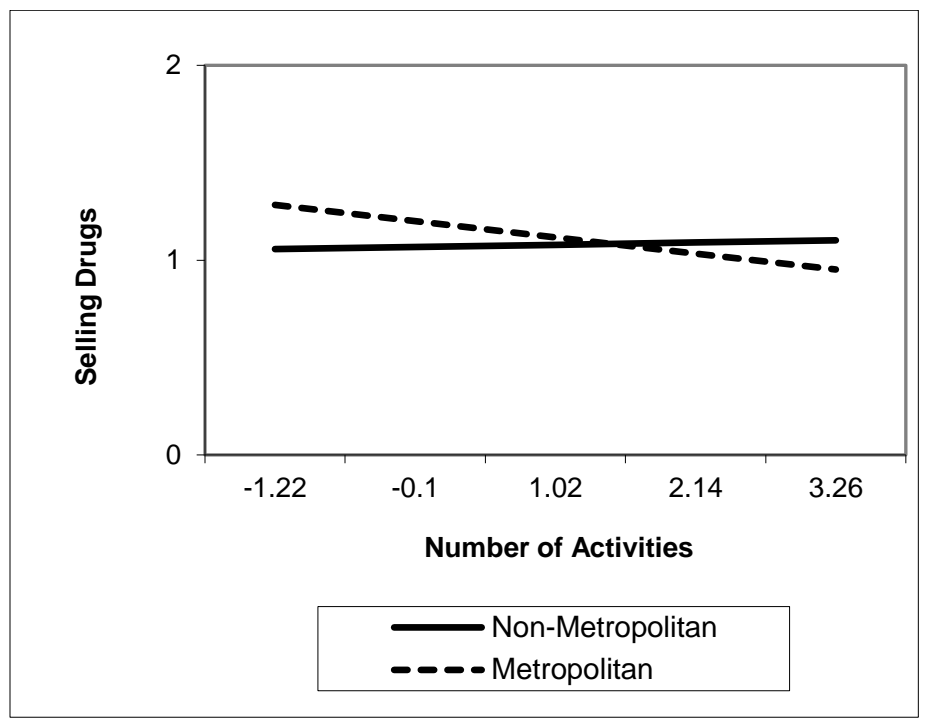


Figure 4

Interaction of Availability of Adult-Led In-School Extracurricular Activities, Gender, and Reported Marijuana Use in the Past 30 Days

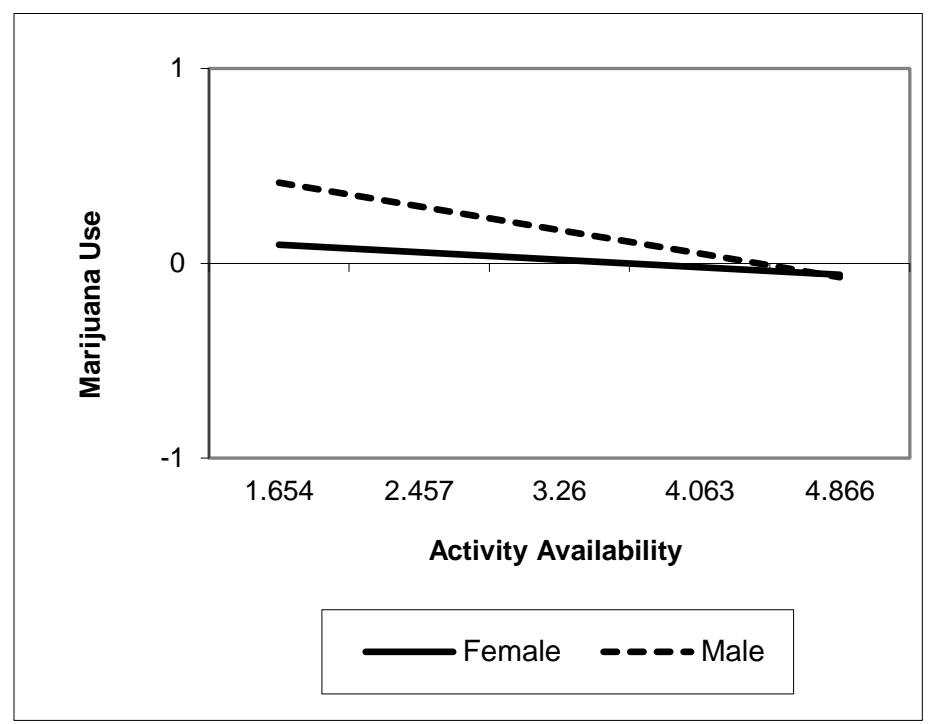


Figure 5

Interaction of Availability of Adult-Led In-School Extracurricular Activities, Metropolitan Status, and Reported Marijuana Use in the Past 30 Days

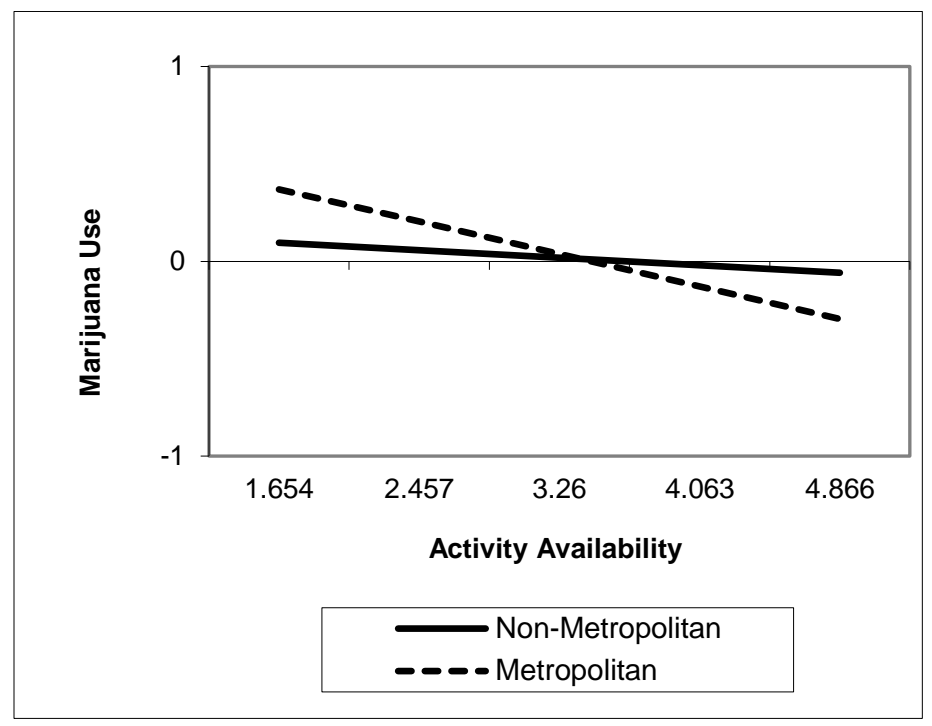


Figure 6

Interaction of Availability of Adult-Led In-School Extracurricular Activities, Gender, and Reported Prescription Drug Use in the Past 30 Days

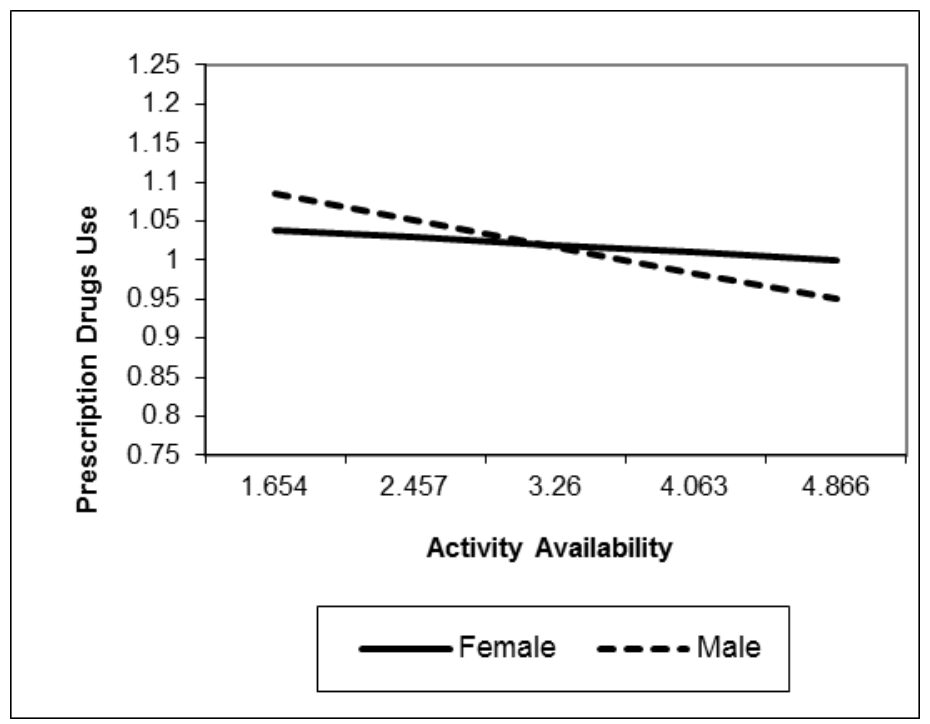


Figure 7

Interaction of Availability of Adult-Led In-School Extracurricular Activities, Metropolitan Status, and Reported Being Drunk or High at School in the Past 30 Days

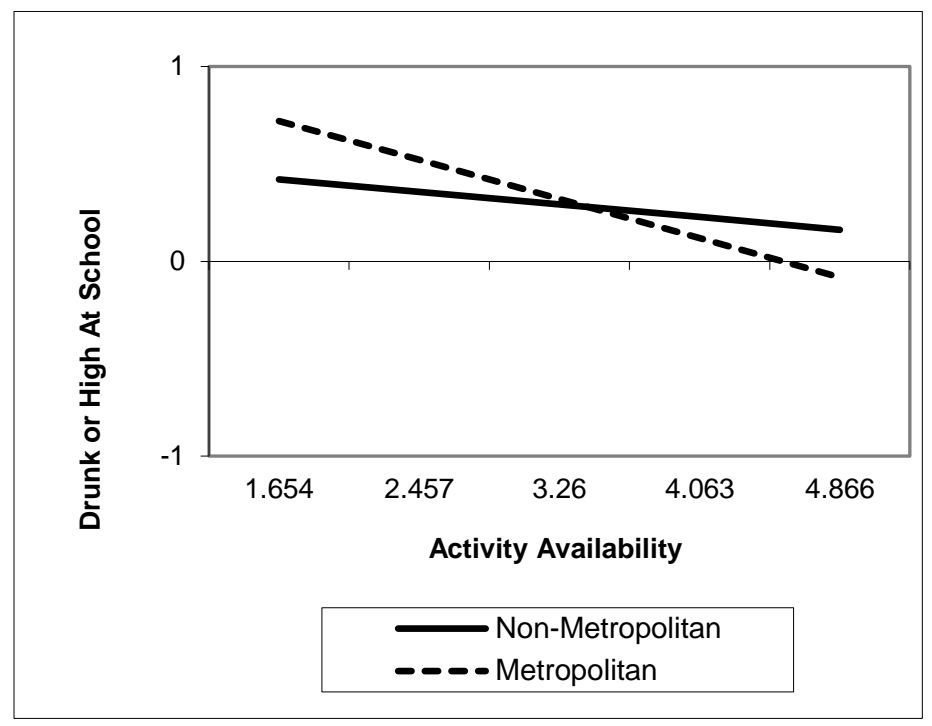


Figure 8

Interaction of Availability of Adult-Led In-School Extracurricular Activities, Gender, and Selling Drugs in the Past 30 Days

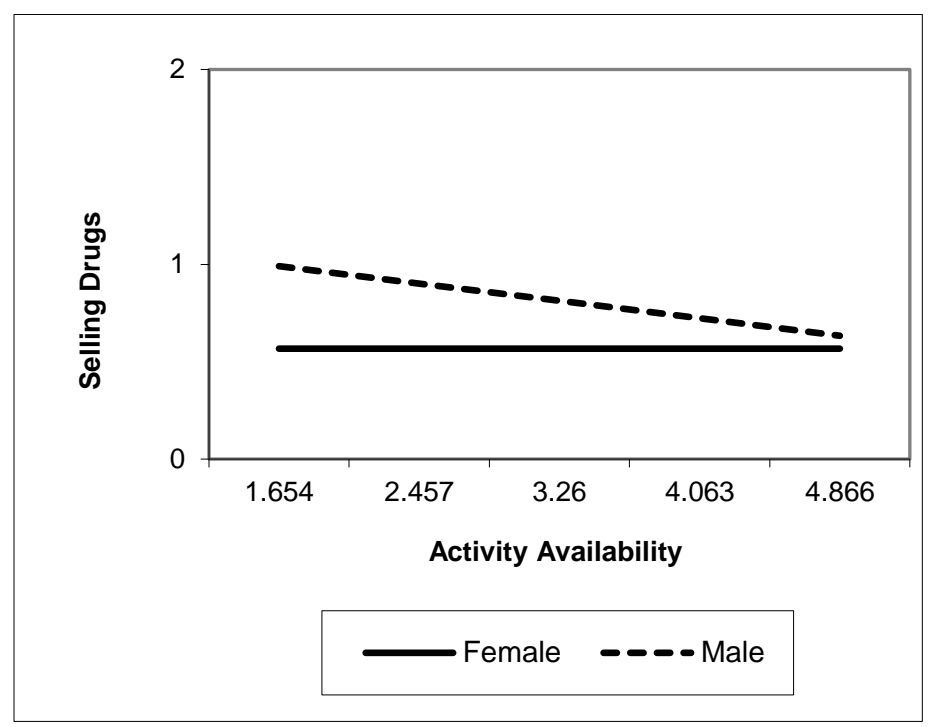


Figure 9

Interaction of Availability of Adult-Led In-School Extracurricular Activities, Metropolitan Status, and Selling Drugs in the Past 30 Days

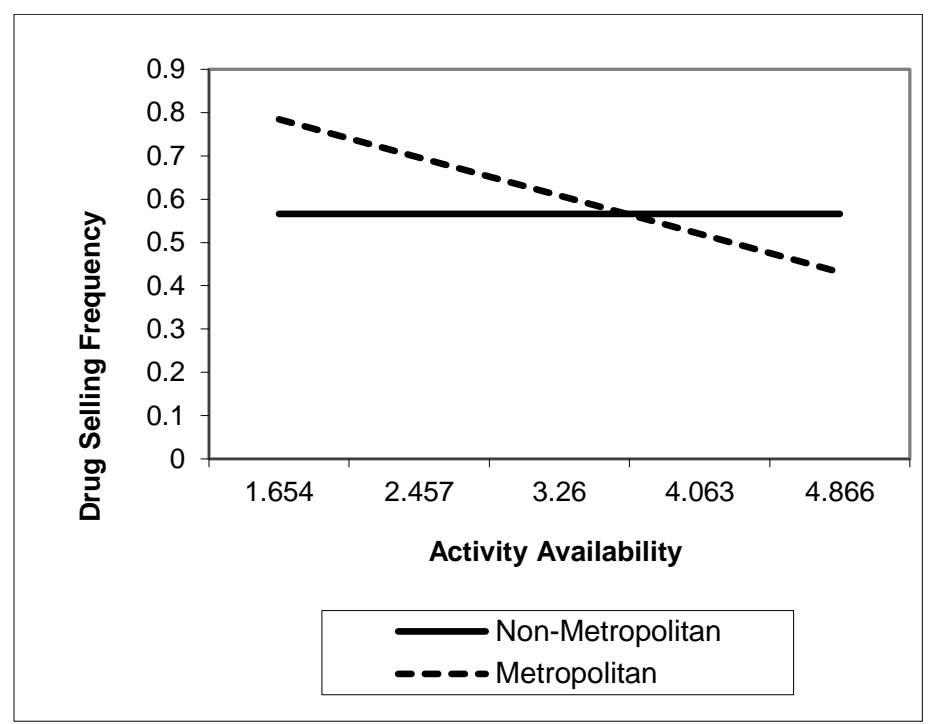


Figure 10

Interaction of Frequency of Involvement in Adult-Led In-School Extracurricular Activities, Reservation Status, and Reported Alcohol Use in the Past 30 Days

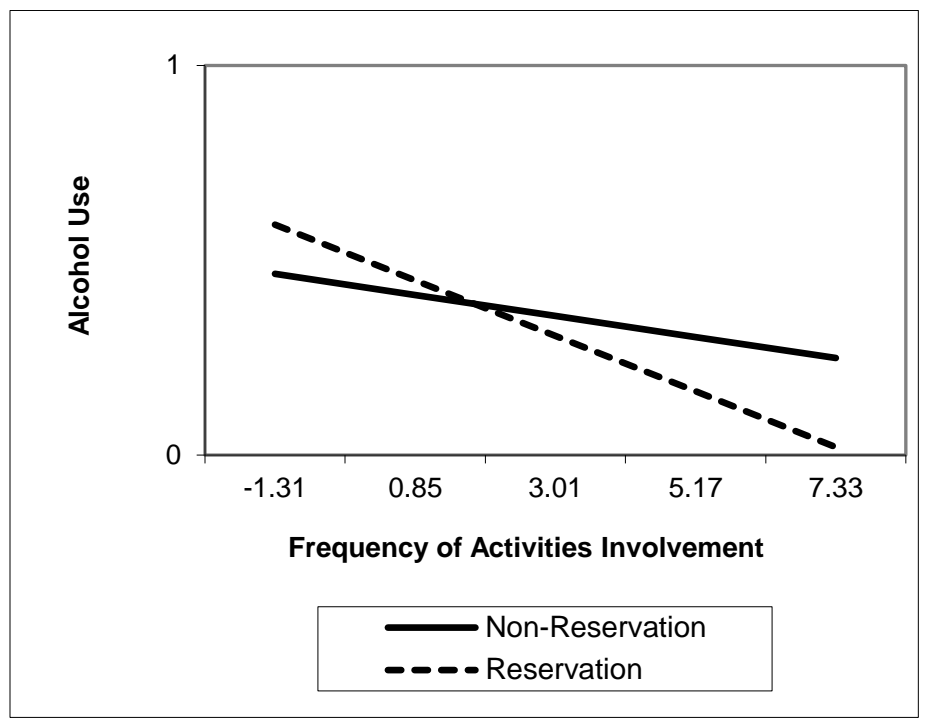




\section{Figure 11}

Interaction of Frequency of Involvement in Adult-Led In-School Extracurricular Activities, Reservation Status, and Reported Marijuana Use in the Past 30 Days

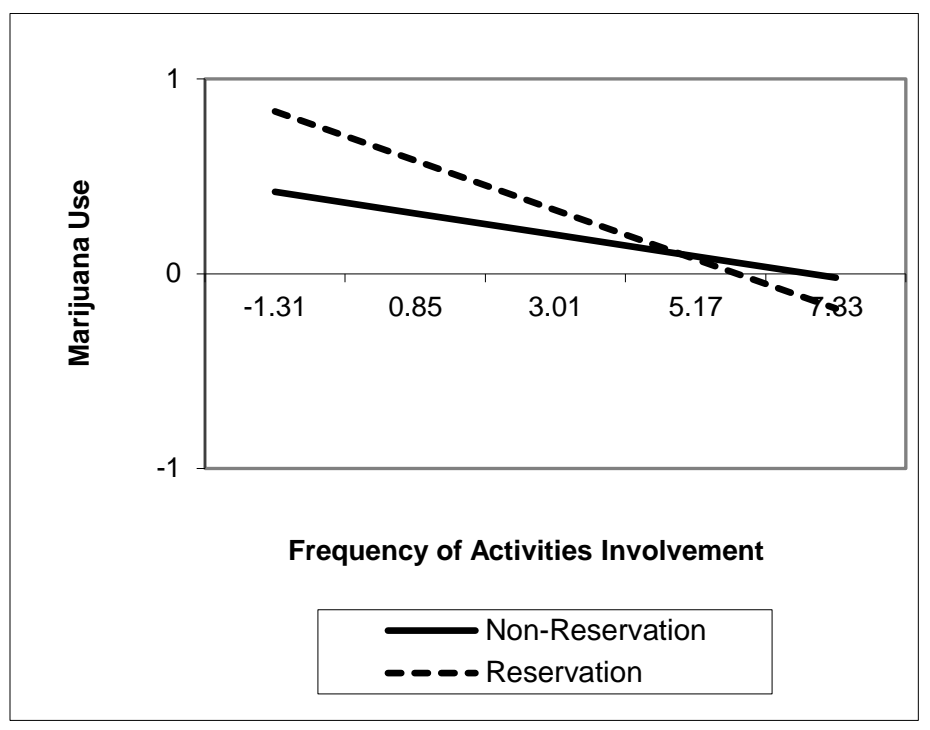


Figure 12

Interaction of Frequency of Involvement in Adult-Led In-School Extracurricular Activities, Metropolitan Status, and Reported Marijuana Use in the Past 30 Days

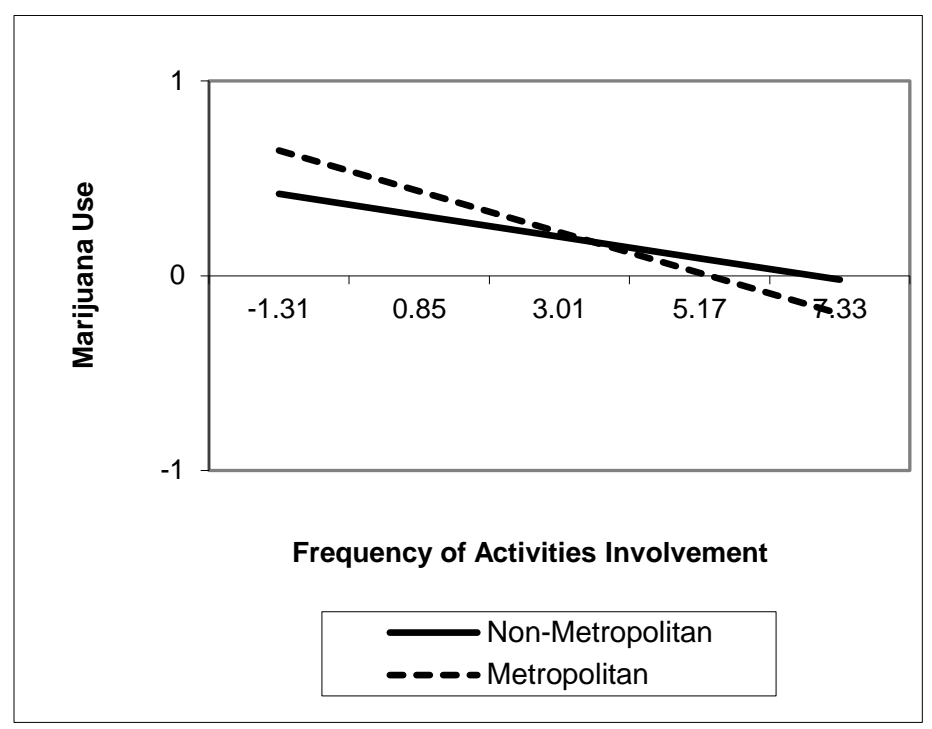


Figure 13

Interaction of Frequency of Involvement in Adult-Led In-School Extracurricular Activities, Reservation Status, and Reported Being Drunk or High at School in the Past 30 Days

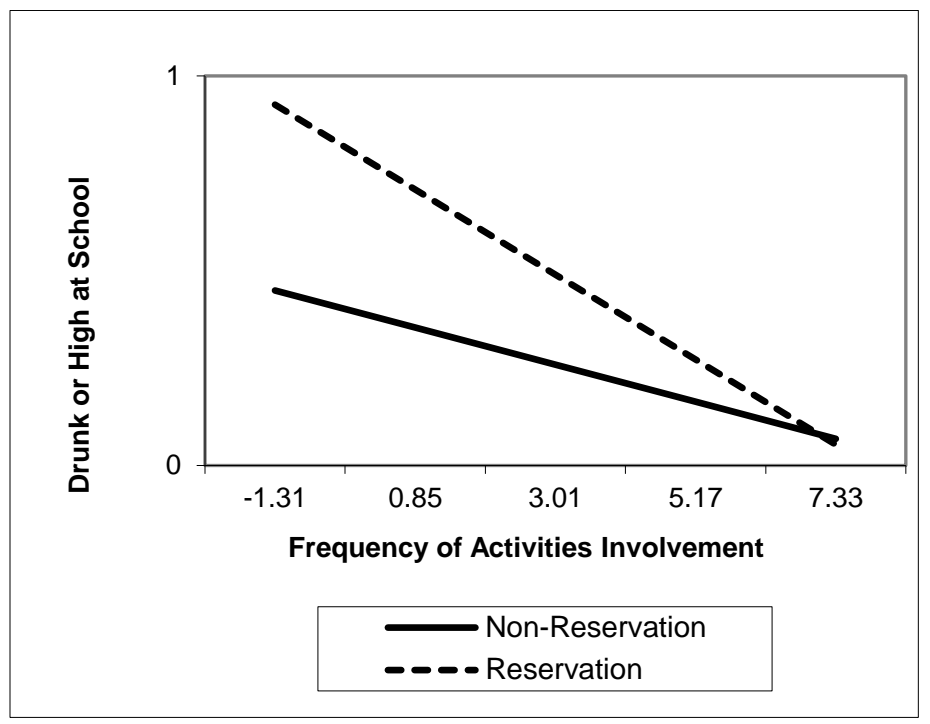


Figure 14

Interaction of Frequency of Involvement in Adult-Led In-School Extracurricular Activities, Metropolitan Status, and Reported Being Drunk or High at School in the Past 30 Days

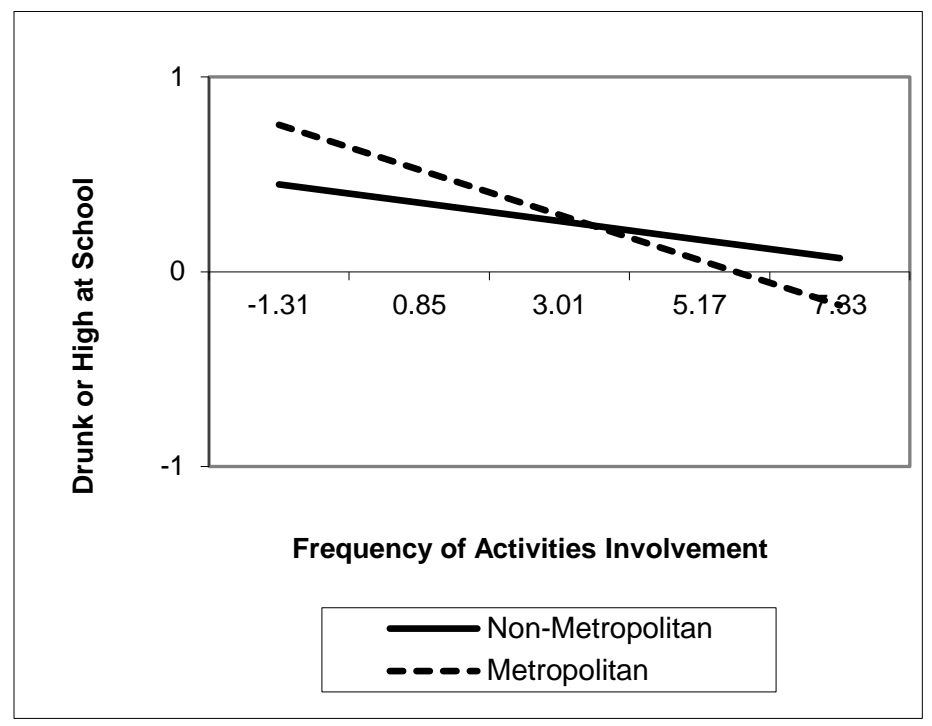




\section{Figure 15}

Interaction of Frequency of Involvement in Adult-Led In-School Extracurricular Activities,

Gender, and Reported Riding with an Intoxicated Individual or Driving a Vehicle While

Intoxicated in the Past 30 Days

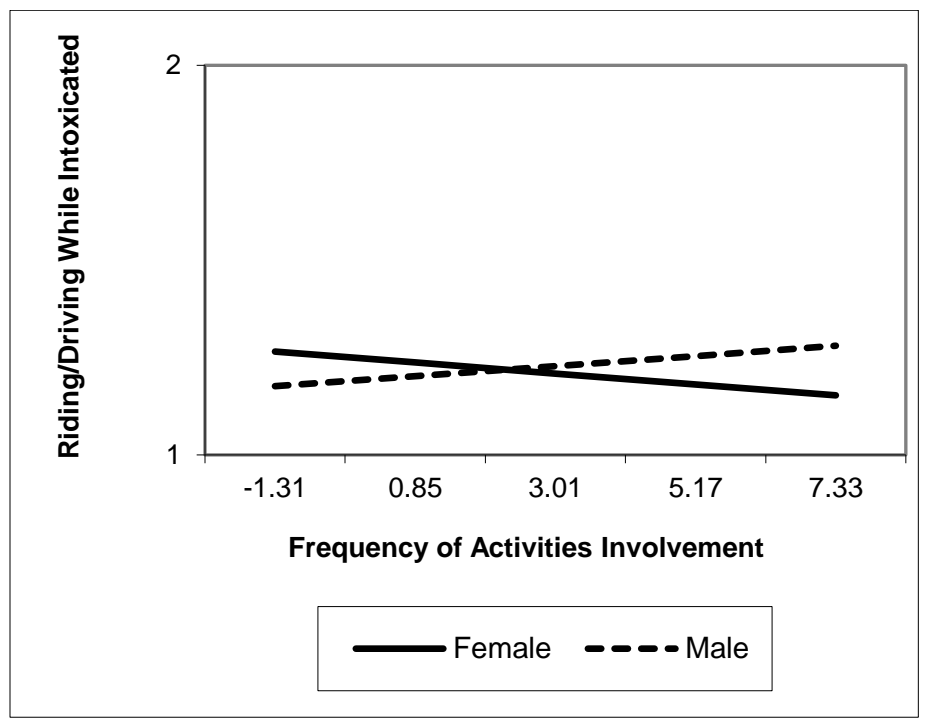


Figure 16

Interaction of Frequency of Involvement in Adult-Led In-School Extracurricular Activities,

Reservation Status, and Reported Riding with an Intoxicated Individual or Driving a Vehicle

While Intoxicated in the Past 30 Days

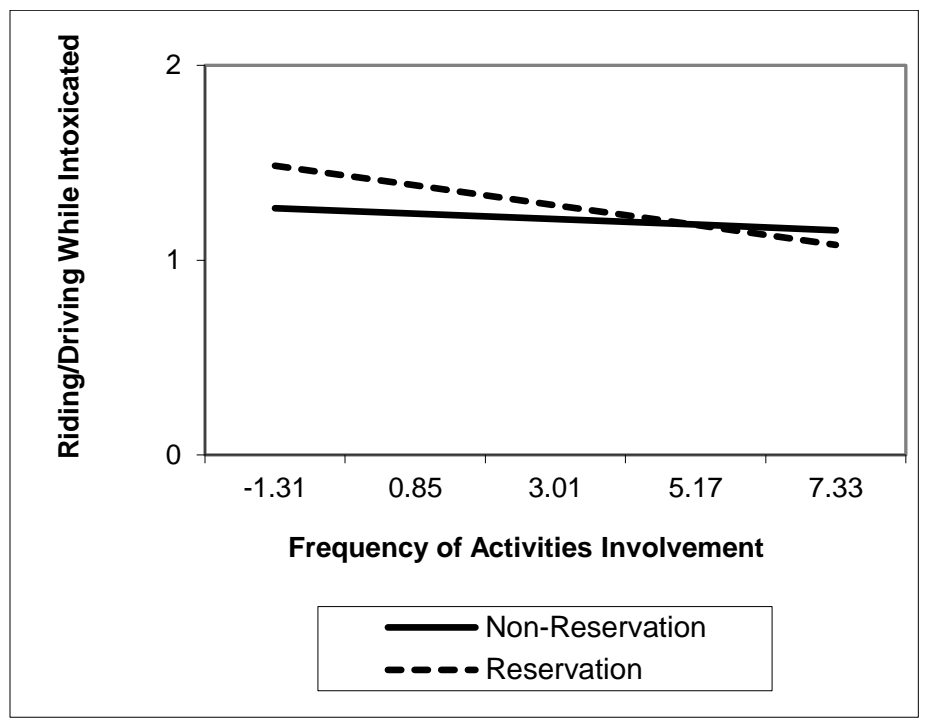


Figure 17

Interaction of Frequency of Involvement in Adult-Led In-School Extracurricular Activities, Metropolitan Status, and Reported Riding with an Intoxicated Individual or Driving a Vehicle While Intoxicated in the Past 30 Days

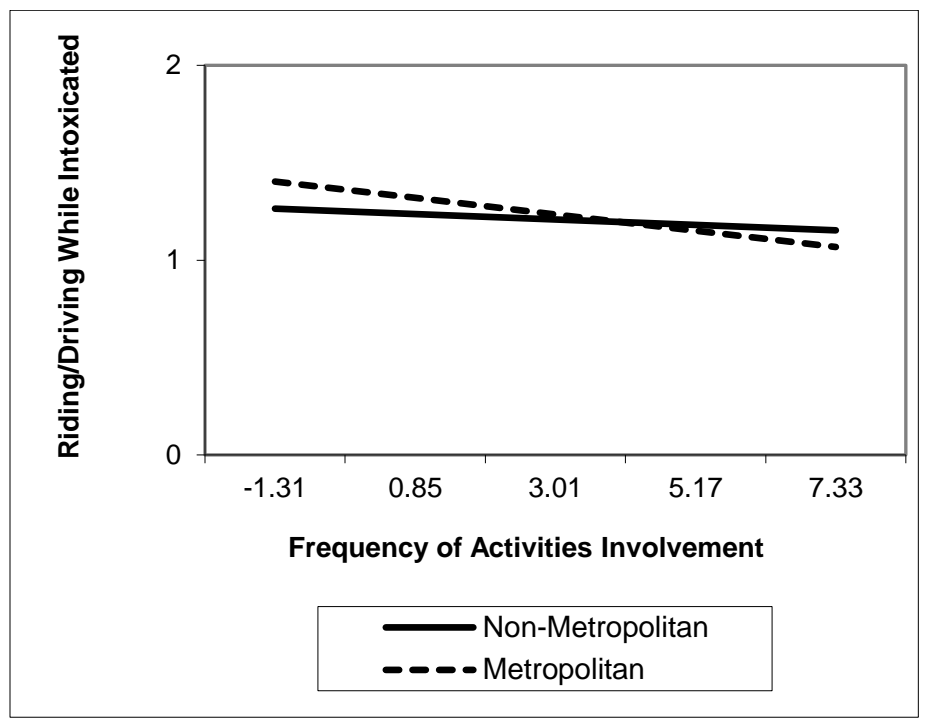


Figure 18

Interaction of Frequency of Involvement in Adult-Led In-School Extracurricular Activities, Metropolitan Status, and Selling Drugs in the Past 30 Days

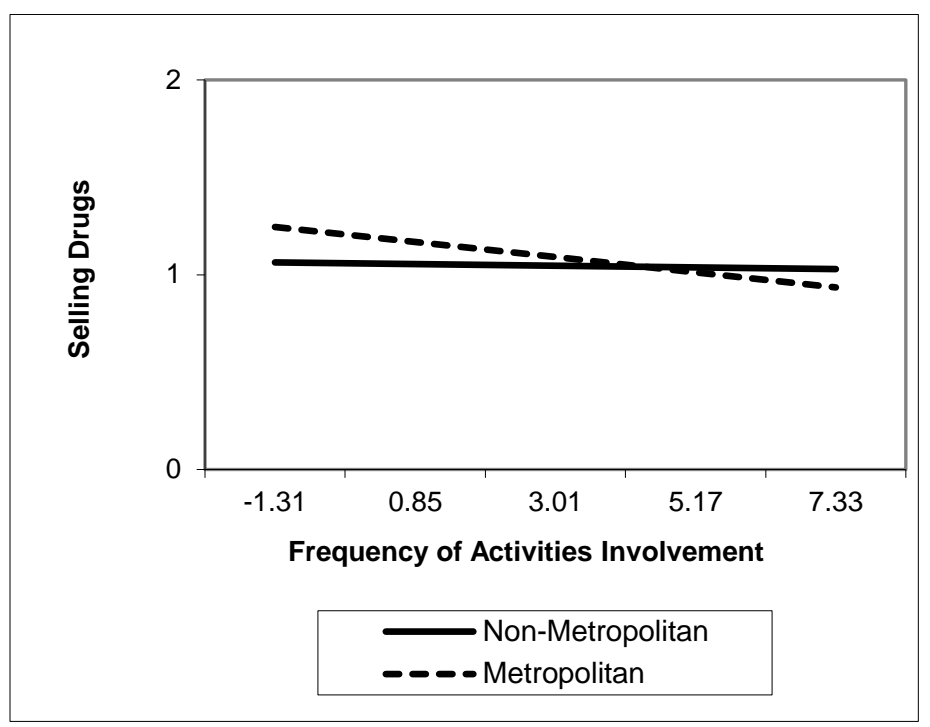


Figure 19

Interaction of Number of Adult-Led In-School Activities Adolescents are Involved in, Metropolitan Status, and Selling Drugs in the Past 30 Days

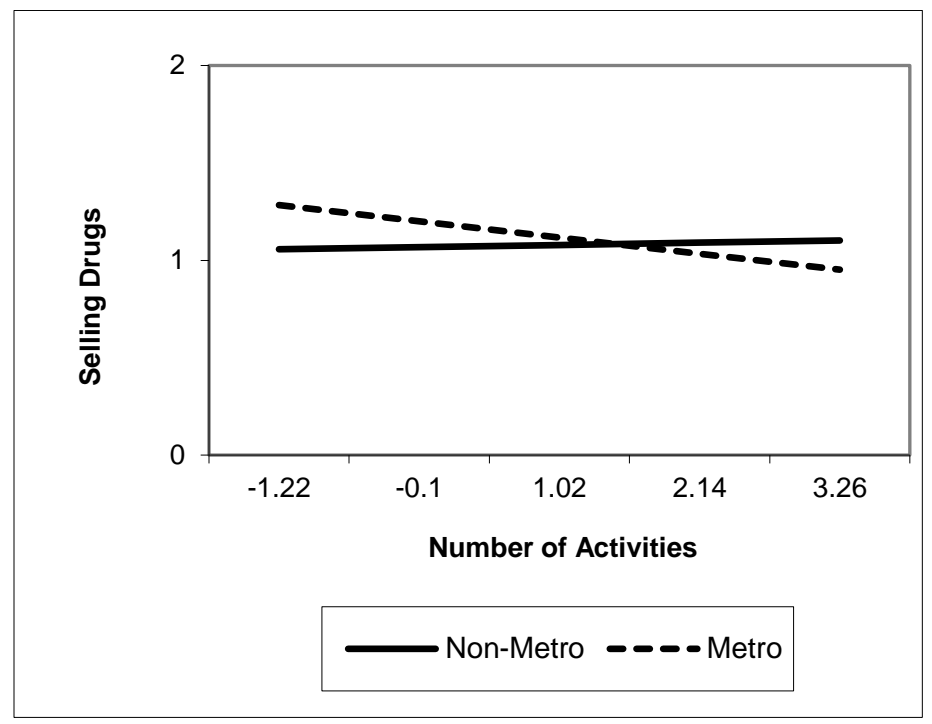

